Bull. Fac. Agric., Cairo Univ. 65:214-226 (2014).

\title{
A SOCIAL STUDY OF SOME DISPLACEMENT NUBIAN VILLAGES
}

\author{
(Received:6.8.2014)
}

\author{
By \\ G.A.G. Elmenofi \\ Agriculture Extension and Rural Development Research Institute \\ Agricultural Research Centre, Giza, Egypt
}

\begin{abstract}
The Southern Valley area possesses a valuable part of Egypt which is Nuba, that has been neglected for years without exerting any developmental efforts to improve people's livelihoods and compensating them for displacement to establish the High Dam.

The High Dam in Aswan Governorate was established as an immediate necessity for Egypt to overcome the River Nile flood and to provide source of electrical power. Unfortunately, the project was implemented without the participation of the Nubians and without paying attention to the Nubian needs and the physiological and social impact on them due to the displacement.

Therefore the current study aimed at portraying the main features and conditions in the displacement villages in order to improve it until the re-settlement of the Nubians in their ancestors land through adopting a national program, which is already mentioned in the current (2014) Egyptian constitution.

The data was collected using the Participatory Rapid Appraisal (PRA) tool (i.e. focus group discussion, pair-wise ranking matrix, and questionnaire) to assure triangulation. The study was carried out in three villages in Nasr El-Nuba district (markaz) which are: "Toshky El-Gharbia", "El-Genina Wa El-Shebak", and "Qatta". The group discussions were conducted with both men and women at the studied three villages. and data were collected in June 2014.

The study revealed that there is a strong desire among the Nubians to be re-settled in their ancestors land once more, especially among youth. Besides, most of the studied villages lack some services and others which need to be improved. Additionally, there is a necessity to establish agricultural and non-agricultural projects that provide job opportunities and reduce high unemployment rates among youth, especially after the major reduction in tourism, which was one of the major income resources, as most of them are engaged in agricultural activities only because no other jobs are offered, but they indicated if conditions of agriculture improves they will continue working.

As for Nubian women, they are educated and work with no societal opposition, but they need awareness especially in maternal issues and also to provide small handicrafts activities within their households that help to preserve the traditional Nubian products.
\end{abstract}

Key words: Nuba, settlement, youth.

$$
\begin{aligned}
& \text { دراسة اجتماعية عن بعض قرى التهجير النوبية } \\
& \text { جيهان عبد الغفار المنوفى } \\
& \text { معهد بحوث الارشاد الزراعى والتنمبة الريفية ـ مركز البحوث الزراعية ـ الجبزة ـ مصر }
\end{aligned}
$$

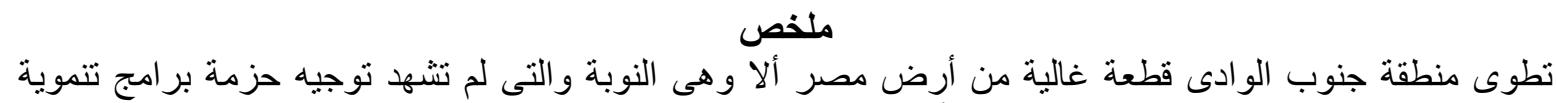

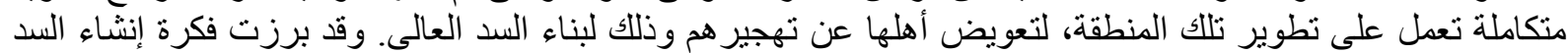

العالي في أسوان وفوق أرض النوبة لتحمي مصر من خطر الفيضان وتعمل على توفير مصدر للطاقة، لكن لم يتم الاهنمام 


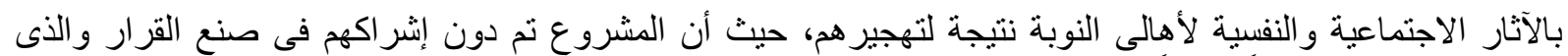

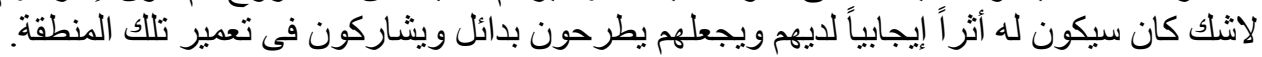

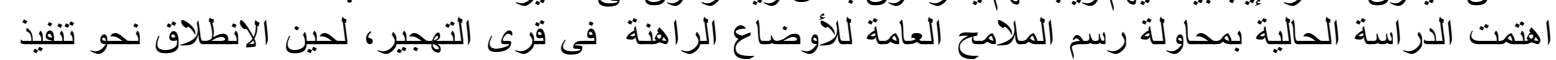

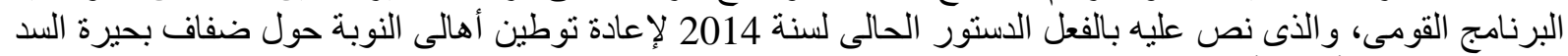

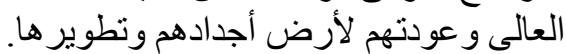

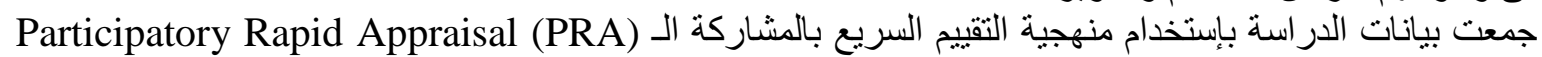

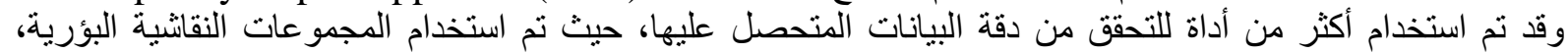

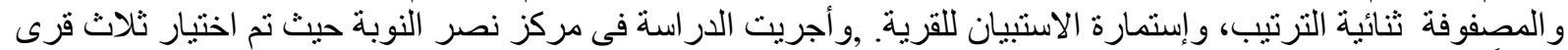

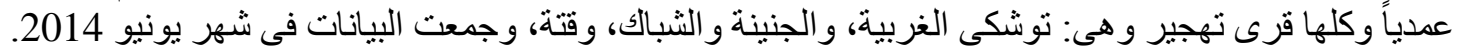

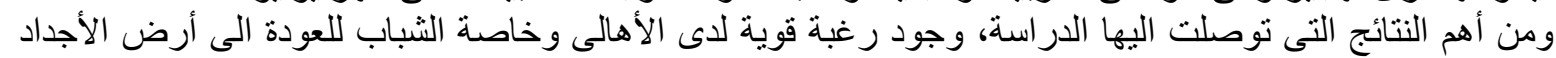

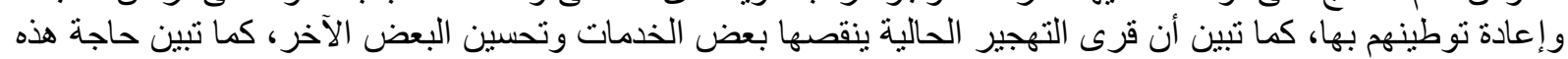

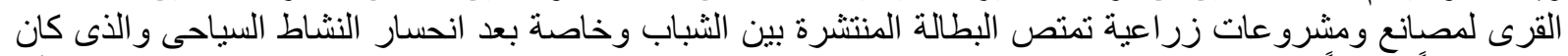

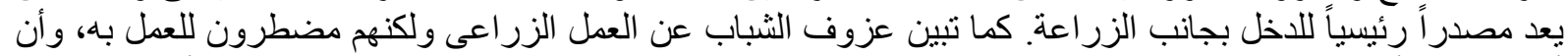

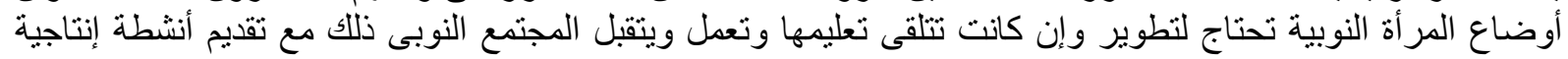
تعتمد على إحياء التراث النوبة أنى لنق، ورفع قدر اتهن الحياتية.

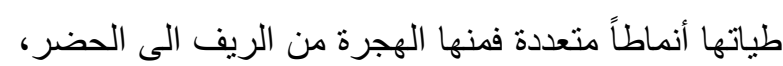

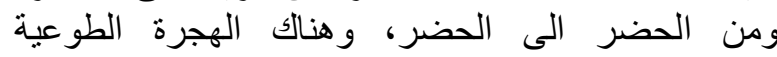

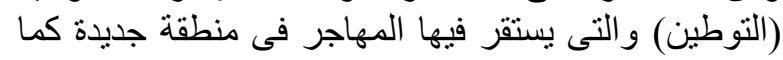

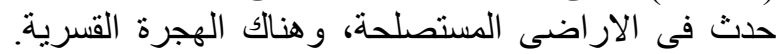

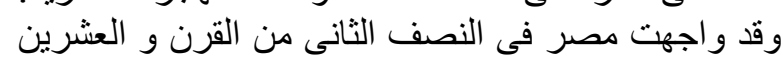

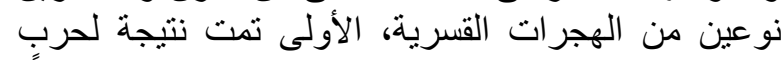
1967 و التى حدث فئها تهجير لسكان التهان مدن القناة تحديداً،

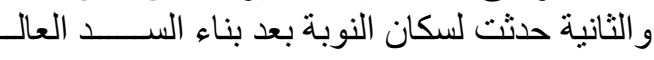
(Zohary and Harrell-Bond 2003 ) لاشك أن إنشاء السدود قد أسهم فى تحقيق التنمية

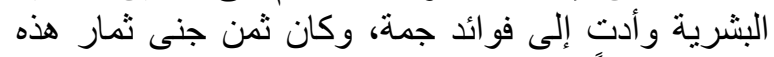

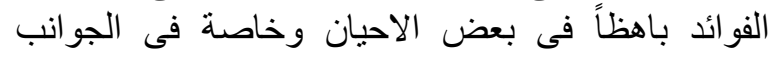

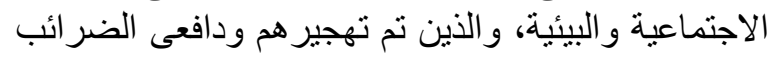

. The World Commission of Dams Report, 2000) تعرض النوبيون للتهجير فى نهاية القرن التاسع عشر،

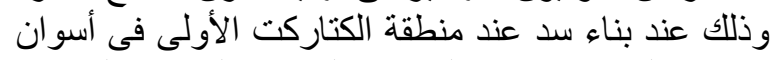

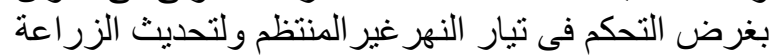

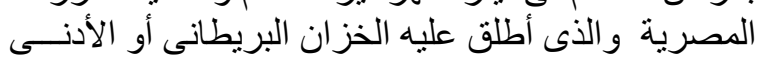
British or Low dam

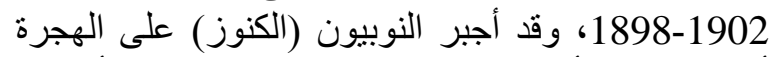

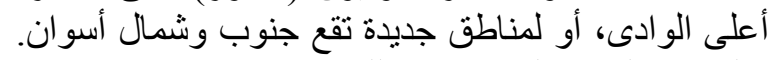

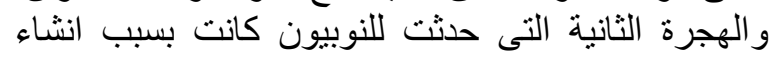
السد العالى (Zabrana, 2013).

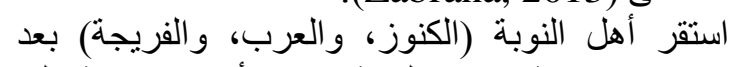

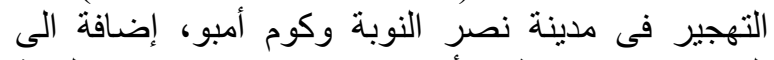

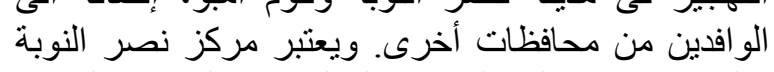

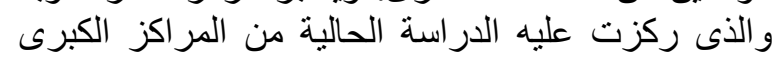

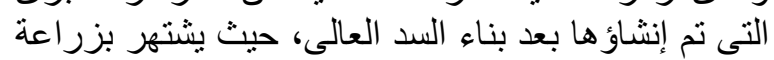

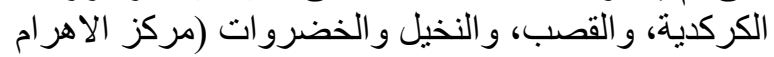
للار اسات الاستر اتيجية، ولفية 2003). ويسكن النوبيون المنطقة الواقعة جنوب النئنة مصر وشمال السودان، وشملت الحضارة النوبية ثلاث ممالك أولها لهان نبتة،

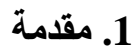

تحمل منطقة جنوب الو ادى فى جنباتها مقومات تنموية

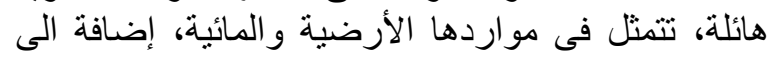

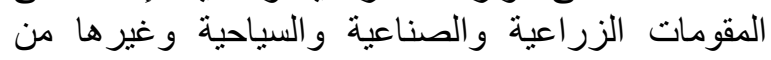

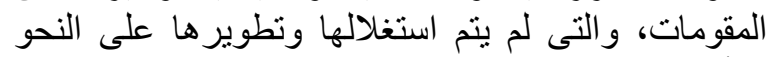

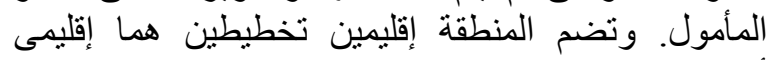

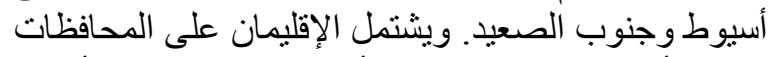

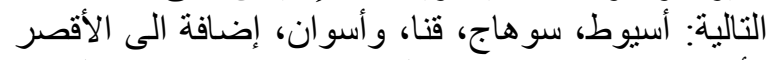

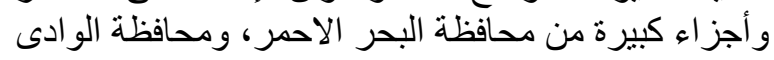
الجديد.

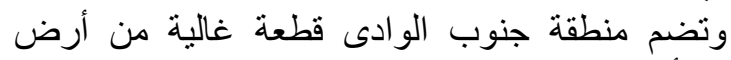

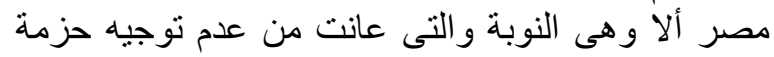

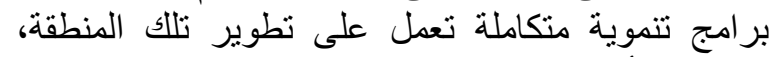

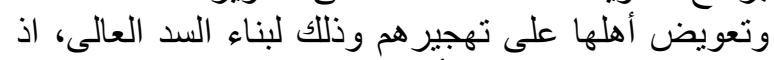

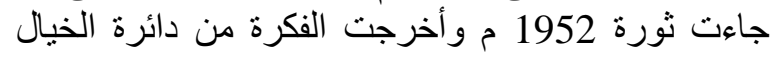

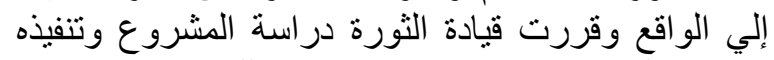

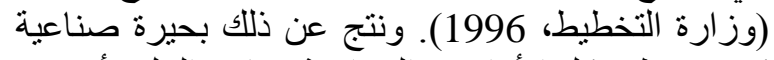

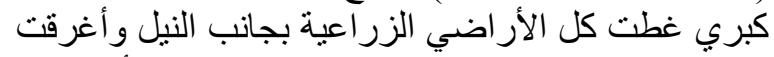

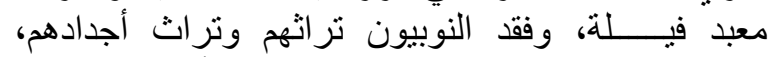

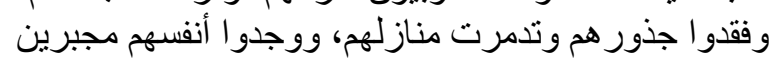

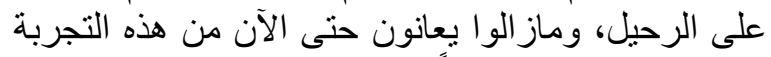
و التى غيرت الريل، وياتهم تماماً.

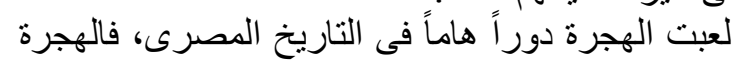

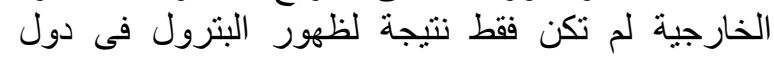

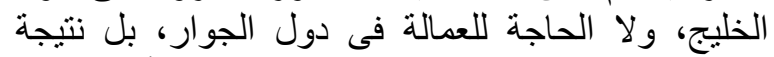

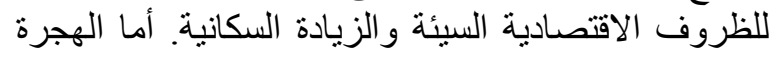

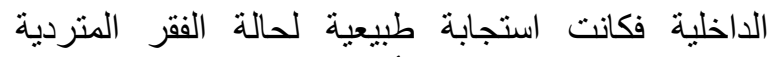

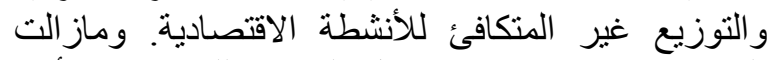

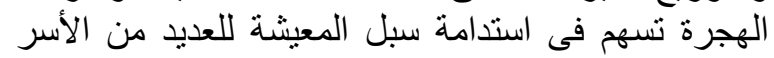

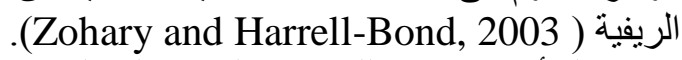
و هناك أنو اع متعددة للهجرة، فالهجرة الداخلية تحمل فى 
و الاستراتيجية، 2003). وقد تم اختيار ثناث قرى عمدياً

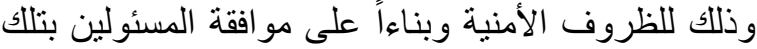

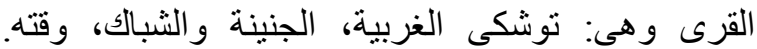

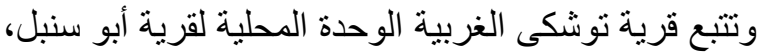
وتتبع قرية قته الوحدة المحلية لقرية قورتة، وتلتية التبع الجنينة و والثباك، الوحدة المحلية لقرية عنية الزية.

2.2. المجال البشري والزمنى للاراسة الترة

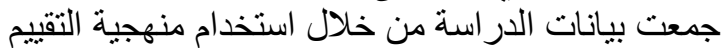

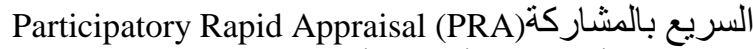

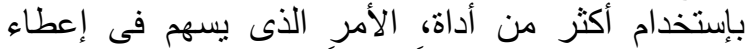
صورة واقعية وتوصيفاً دقيقاً للأوضاع الأو الاجتماعية

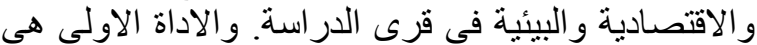

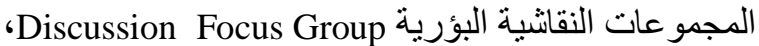

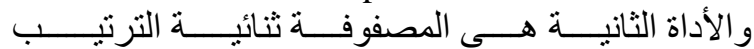
Pair-wise ranking matrix و وتعتمد على تحديد المشكلات

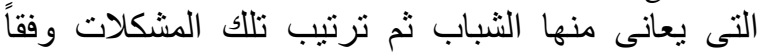

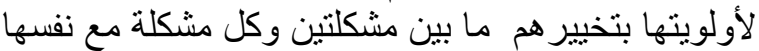

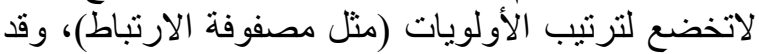
يسفر الأمر فى النهايةعلى مشكلتين أو أكثرحسب الترابت الترتيب.

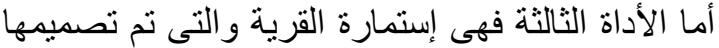

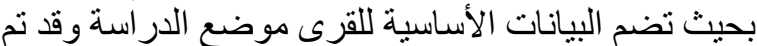

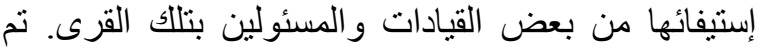

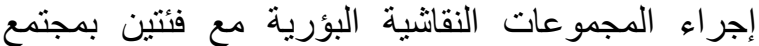

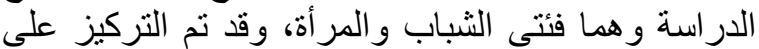

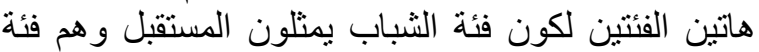

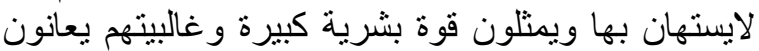

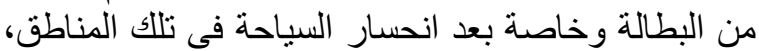

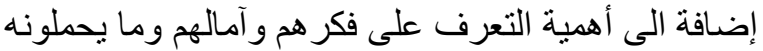

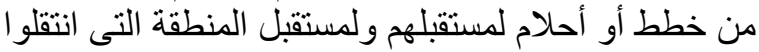
واستقروا فيها. ففى مركز نصر النوبة ـموضع الفولة الدراسةـ تمثل الفئة العمرية 5-10 سنوات الفئة الفئة القاعدية بالنسبة الفية لللكور ، والفئة العمرية 10-15 سنة الفئة القاعدية بالنسبة الفية الفية للإناث. وبلغت قوة العمل كنسبة مئوية من إجمالى السكان

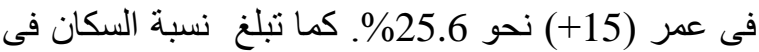

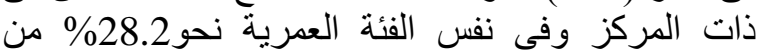
إجمالى السكان بمحافظة أسوان (تقرير التنمية البشرية، محافظة أسو ان، 2005).

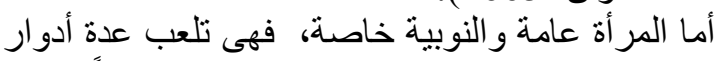

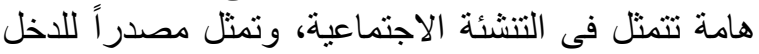

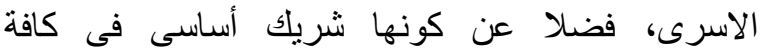
القطاعات القومية، كما لايمكن إغفال مشاركتها المجنية المجتمعية

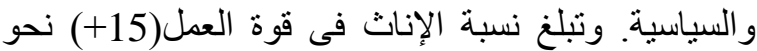

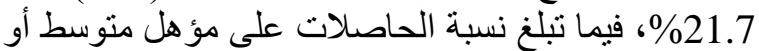
أعلى نحو 24\% \% (تقرير التنمية البشرية، محافظة أسوان،

وقد تم عقد ستة مجمو عات نقاثية متعمقة بقرى الدر اسة

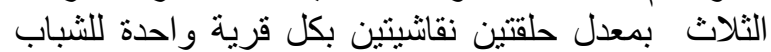
والأخرى للسيدات وتراوح عدد الحضور في كل بل حلقة
ثم كرمة، واّخرها مروي في السودان. ويتحدث أهل النوبة اللغة النوبية وتتقسم إلى قسمين أساسيين الكنزيه و والفاديجيه وتنقسم إلى خمس لهجات أو أكثر في مناطق مختلفة الكنة ما بين

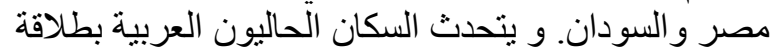
مع لغات أخرى كالإنجليزية و الفرنسية والإنيطالية بحكم الإنية

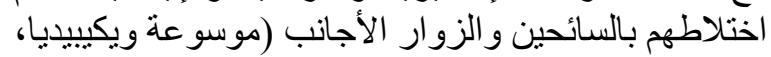
تم التصفح فى يناير 2014). وعلى الرغم من مرور سنواتل التوات عديدة على تهجير

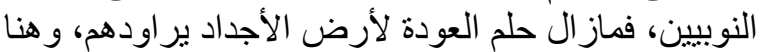

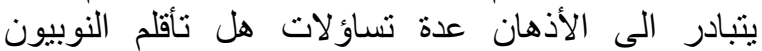

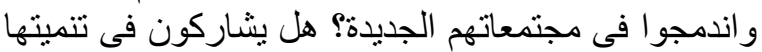

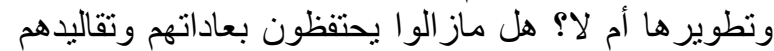

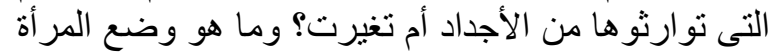

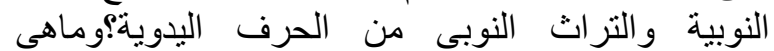

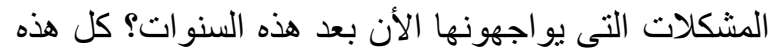

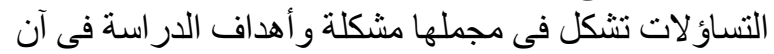

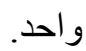

ومن ثم تطمح الدراسة الحالية فى تقديم صورة دقيقة

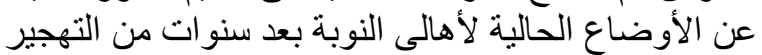

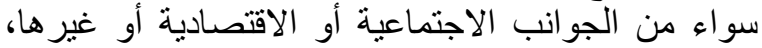

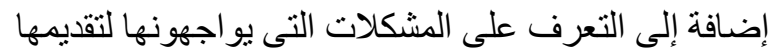

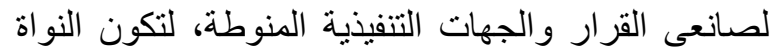

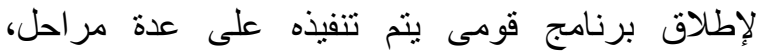
بمشاركة بعض الجهات المعنية سو اء حكومية الونية أو منظمات

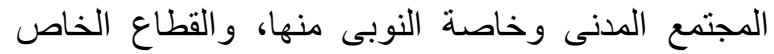

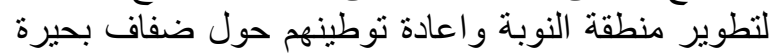

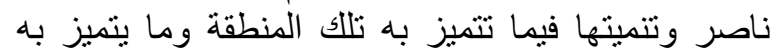

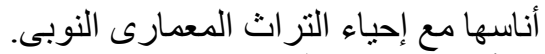

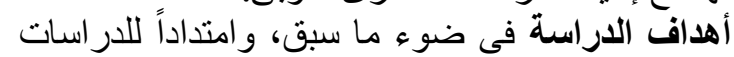

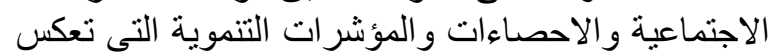

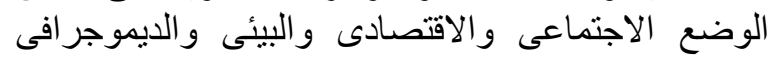

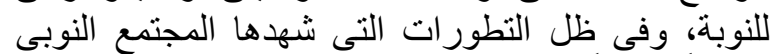

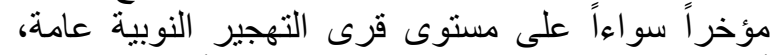
أومركز نصر النوبة خاصة، بمكن بلورت التهي أهداف الدراسة

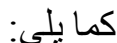

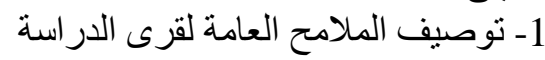

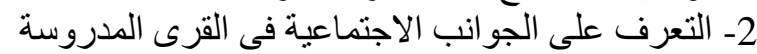

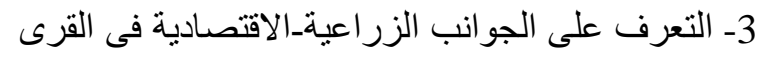

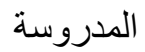
4-تحديد وترتيب أهم المشكلات المجتمعية

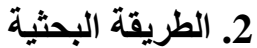

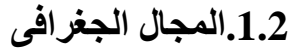

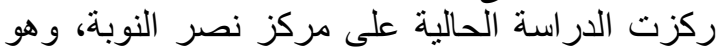

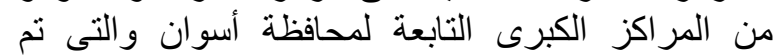
إنشاؤها بعد بناء السد العالى لتهجير أهالى التهائ النوبة القديمة

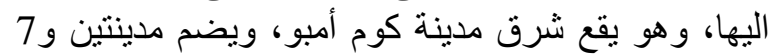
مجالس قروية مركز الاهرام لللراسات السياسية 
1.3. توصيف الملامح العامة لقرى الدراسة

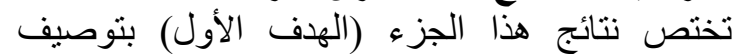

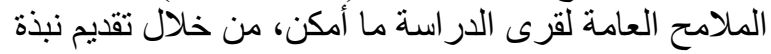

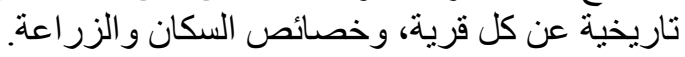

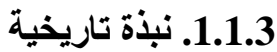
تم التوطين فى قرية نوشكى الغربية عام 1963، وبية وبيلغ

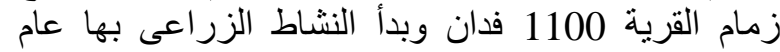

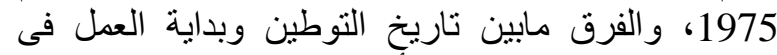

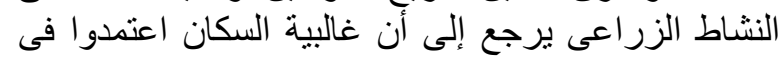

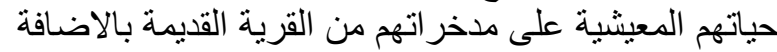

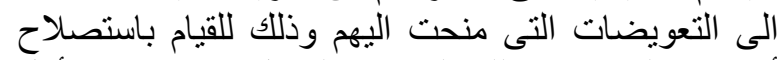
أراضى القرية فى تلكى الفترة، و التكافل الاجتماعى لأهل

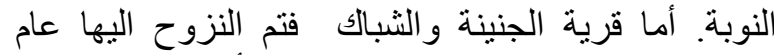

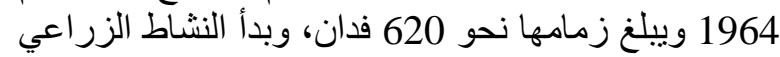

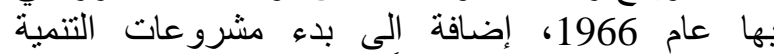

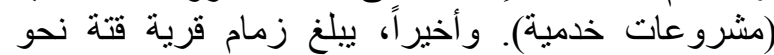

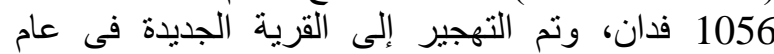

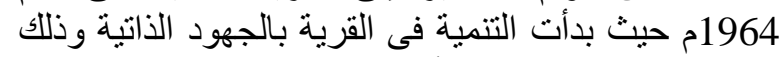
حتى عام 1974، حيث بدأت التنمية فى القرى الجديدة من التردية

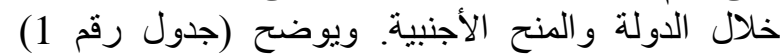

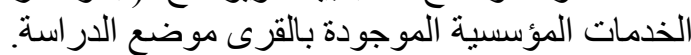

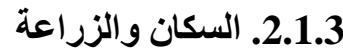

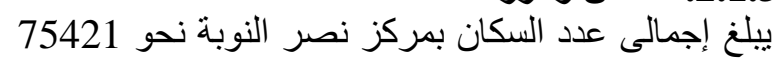

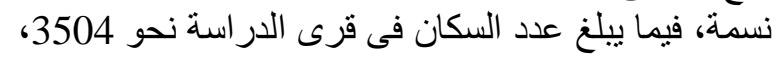

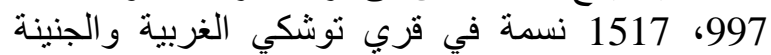

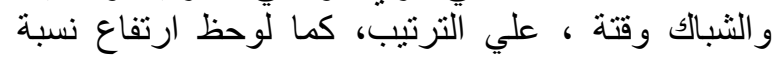

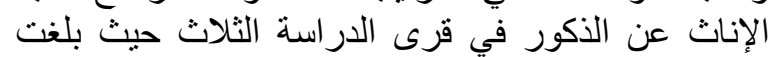

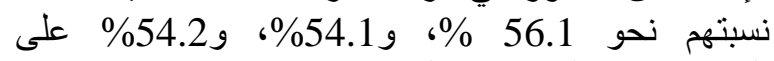

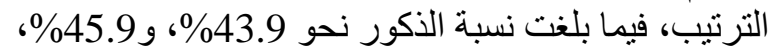

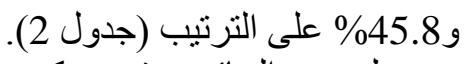

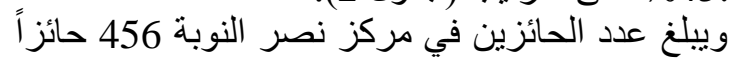

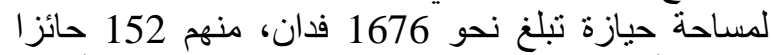

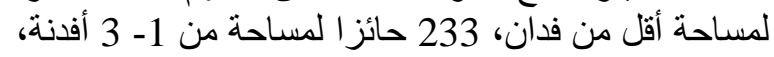

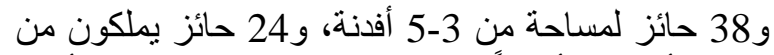

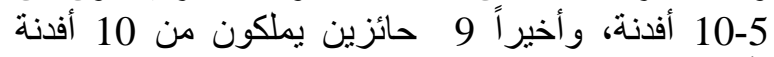

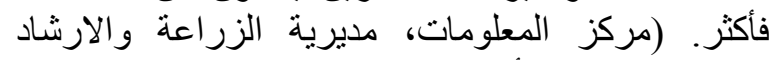
الزر اعى، محافظة أسوان، 2012).

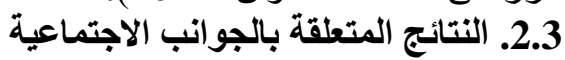

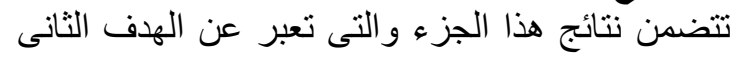

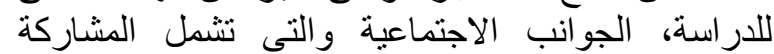

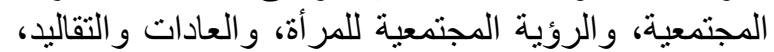

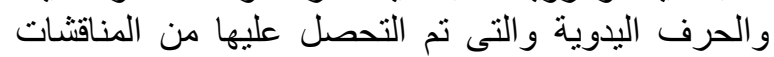
الجماعية البؤرية للشباب والئى السيدات.

1.2.3. 1.المشاركة المجتمعية المباعية

توجد دافعية للمشاركة المجتمعية لإى أهالى المئى القرى

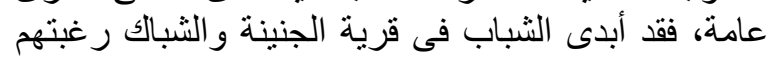

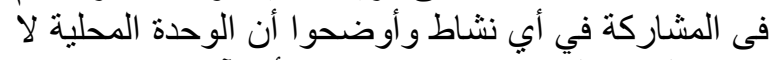

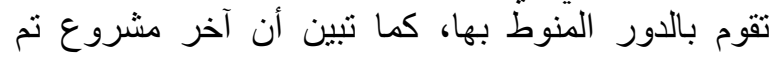
بالقرية كان رصف الطرق الداخلية منذ ثلاث شُهور.

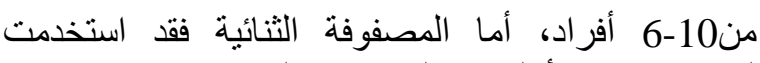
لتحديد وترتيب أولويات المشكلات المنات المجتمعية. وقد تم جمع

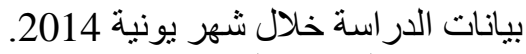

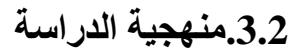
تعتبر الدراسة الحالية من الدراسات الاستطلاعية ومن

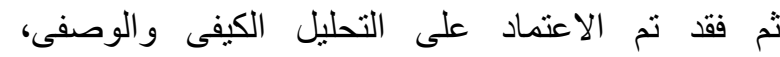

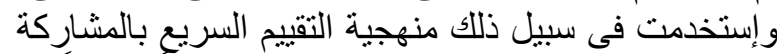

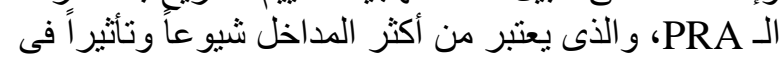

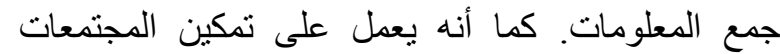

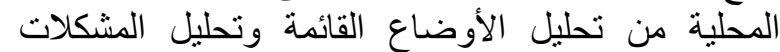

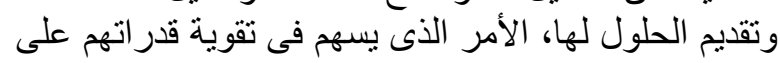

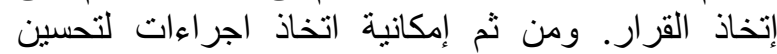

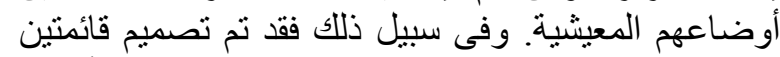

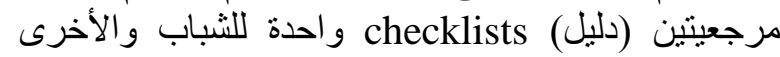

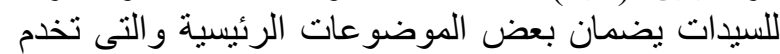
الزر اعى و الاقتصادى. فيما عكست استمارة القرية البيانات

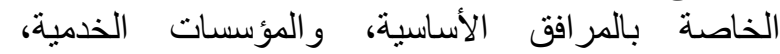

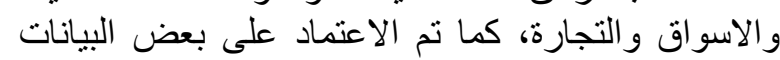

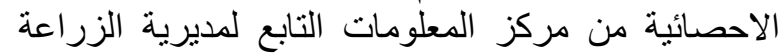

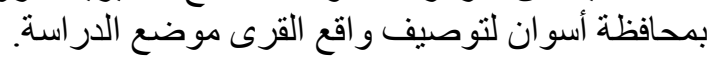

1.3.2 المفاهيم الاجرائية 1.3.2

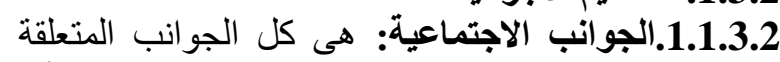

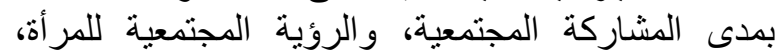

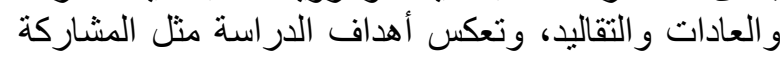

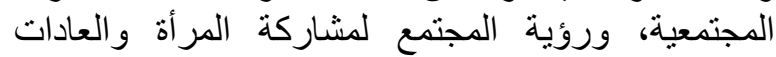
و التقاليد، و النشاط ورو الحرف اليجئية اليدوية.

2.1.3.2. الجوانب الزراعية_الاقتصادية: كافة الأنشطة

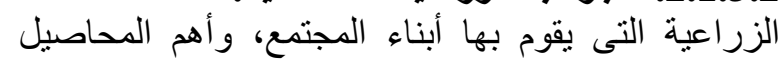

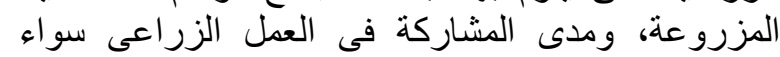

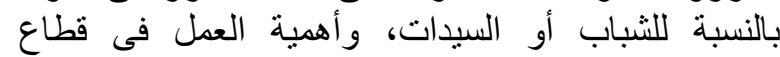

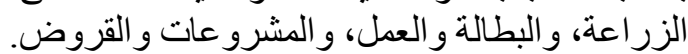

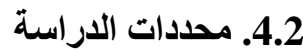

أ) صعوبة الوصول الى الى بعض القرى النوبية لبعدها

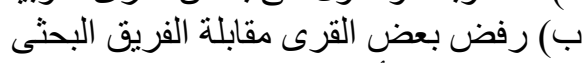

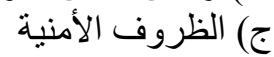

د) صعوبة الوصول الإنبة لمجموعات الثباب فى الصباح إما

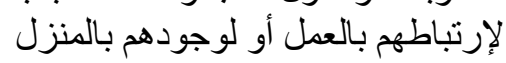

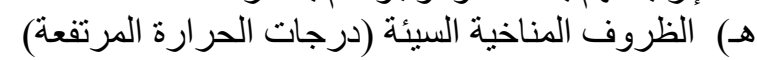

\section{3. نتائج الدراسة الميدانية}

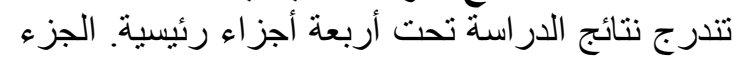

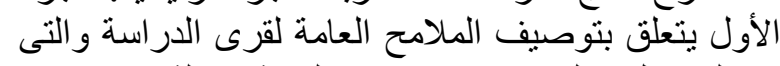

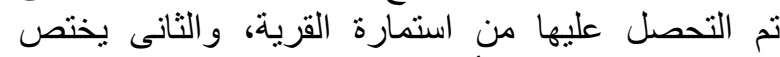

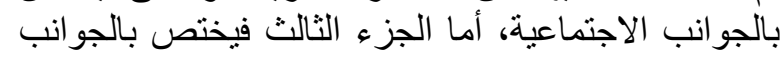

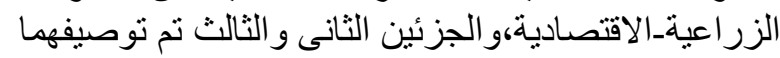

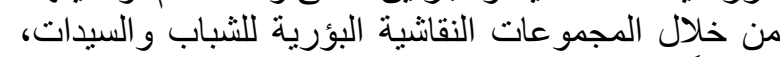

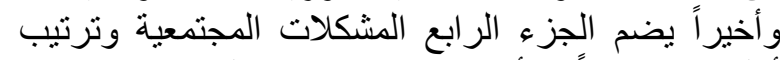

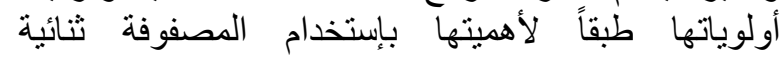
الأبعاد،وتعكس كل هذه الاجز اء فى مجملها أهداف الدراسة 
جدول (1): الذدمات المؤسسية الموجودة بالقرى موضع الدراسة

\begin{tabular}{|c|c|c|c|c|c|c|}
\hline \multicolumn{6}{|c|}{ الوحدة المحلية } & \multirow{5}{*}{ المؤسسات الخدمية } \\
\hline & & \multirow{2}{*}{\multicolumn{2}{|c|}{ القربية }} & \multirow{2}{*}{\multicolumn{2}{|c|}{ أبو سمبلة }} & \\
\hline \multicolumn{2}{|c|}{ هورتة } & & & & & \\
\hline \multicolumn{2}{|c|}{ قته } & \multicolumn{2}{|c|}{ الجنينة و الثباك } & \multicolumn{2}{|c|}{ توشكى الغربية } & \\
\hline حالتها & توجد & حالتها & توجد & حالتها & توجد & \\
\hline جيدة & $\begin{array}{l}- \\
\sqrt{ } \\
- \\
-\end{array}$ & منخفة & $\begin{array}{l}\bar{V} \\
- \\
-\end{array}$ & جيدة جيدة جيدة & $\begin{array}{l}\sqrt{ } \\
\sqrt{ } \\
\sqrt{ } \\
\sqrt{ }\end{array}$ & 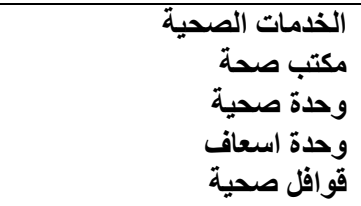 \\
\hline $\begin{array}{l}\text { جيدة } \\
- \\
- \\
-\end{array}$ & $\begin{array}{l}\sqrt{V} \\
- \\
- \\
-\end{array}$ & جيدة & $\begin{array}{l}\sqrt{ } \\
\sqrt{ } \\
- \\
-\end{array}$ & جيدة جيدة & $\begin{array}{l}\sqrt{ } \\
\sqrt{ } \\
\sqrt{ } \\
-\end{array}$ & مدرسة مدرسة ابتدائى التئيمية \\
\hline $\begin{array}{l}\text { جيدة } \\
- \\
- \\
-\end{array}$ & $\begin{array}{l}\sqrt{ } \\
- \\
- \\
-\end{array}$ & $\begin{array}{l}\text { جيدة } \\
- \\
- \\
-\end{array}$ & $\begin{array}{l}\sqrt{ } \\
- \\
- \\
-\end{array}$ & منتوسطة & $\begin{array}{l}\sqrt{ } \\
\sqrt{ } \\
- \\
\sqrt{ }\end{array}$ & 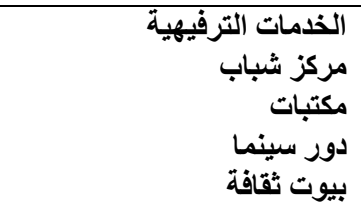 \\
\hline متوسطة & $\bar{v}$ & متوسطة & $\bar{v}$ & متوسطة - & $\bar{V}$ & نقل غائل النقل العام والمواصلات \\
\hline جيدة - جيدة & $\begin{array}{l}\sqrt{ } \\
- \\
\sqrt{ }\end{array}$ & جيدة - جيدة & $\begin{array}{l}\sqrt{ } \\
- \\
\sqrt{ }\end{array}$ & جيدة - جيدة & $\begin{array}{l}\sqrt{ } \\
-- \\
\sqrt{ }\end{array}$ & 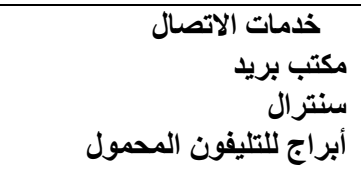 \\
\hline منخفضة & $\begin{array}{l}- \\
- \\
-\end{array}$ & متوسطة - & $\begin{array}{l}- \\
- \\
-\end{array}$ & جيدة & $\begin{array}{l}- \\
- \\
-\end{array}$ & جمقية تجميع ارشية ألبان \\
\hline جيدة & $\begin{array}{l}\sqrt{ } \\
-\end{array}$ & جيدة & $\begin{array}{l}\sqrt{ } \\
\sqrt{ }\end{array}$ & جيدة & $\begin{array}{l}\sqrt{ } \\
\sqrt{ }\end{array}$ & 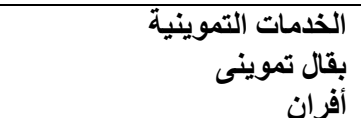 \\
\hline منخفضة & $\sqrt{ }$ & جيدة & $\sqrt{ }$ & جيدة & $\sqrt{ }$ & جمعيات أهلية \\
\hline جيدة جيدة & $\begin{array}{l}\sqrt{ } \\
\sqrt{ } \\
\sqrt{ }\end{array}$ & جيدة & $\begin{array}{l}\sqrt{ } \\
\sqrt{ } \\
\sqrt{ }\end{array}$ & متوسطة & $\begin{array}{l}\sqrt{ } \\
\sqrt{ } \\
-\end{array}$ & 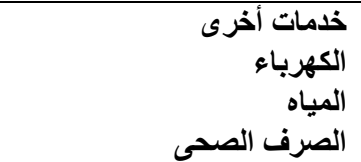 \\
\hline
\end{tabular}

المصدر : استمارة القرية

جدول (2): أجمالى عدد السكان والأسر بقرى الاراسة_مركز نصر النوبة، 2012

\begin{tabular}{|c|c|c|c|c|c|c|c|}
\hline \multicolumn{6}{|c|}{ عدد السكان } & \multirow[t]{2}{*}{ القرية } & \multirow[t]{2}{*}{ الوحدة المحلية } \\
\hline علد الاسر & الجملة & $\%$ & إناث & $\%$ & ذكور & & \\
\hline 189 & 3504 & 56.1 & 1965 & 43.9 & 1539 & توشكى الغربية & قرية أبو سمبل \\
\hline 221 & 997 & 54.1 & 539 & 45.9 & 458 & الجنينة والثباك & قرية عنيبة \\
\hline 282 & 1269 & 54.2 & 687 & 45.8 & 582 & قته & قرية قورتة \\
\hline 692 & 5770 & 55.4 & 3191 & 44.6 & 2579 & & \\
\hline
\end{tabular}


الثباب بموضوع التغذية الصحية لهم حيث أفادوا أن النوبه

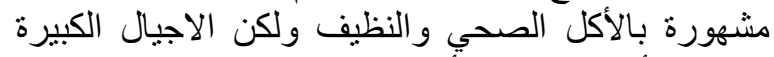

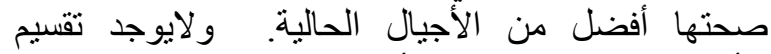

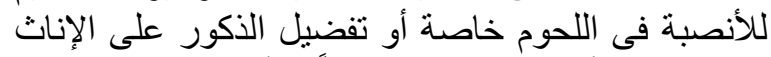

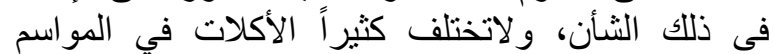

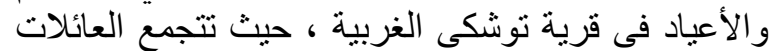

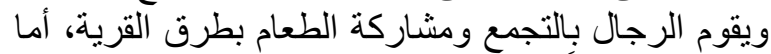

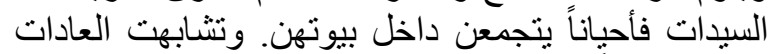

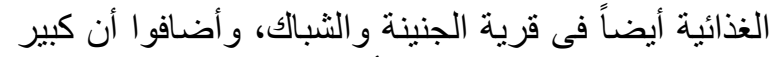

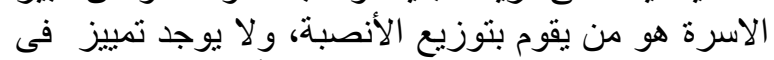

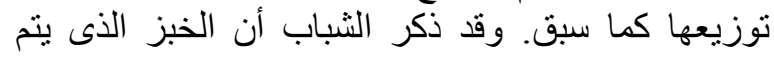

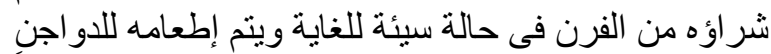

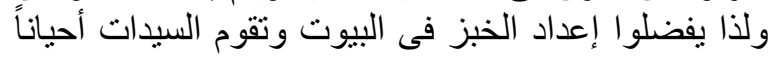

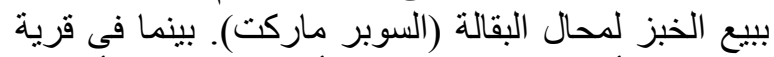
قتته، فإن الأكلات في المواسم والأعياد هي لإلى لحم الأضحية

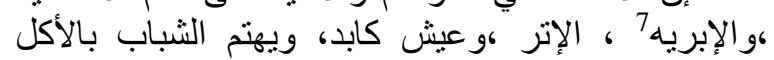

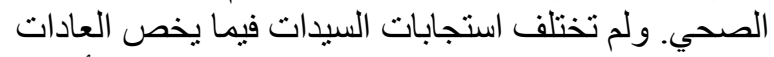

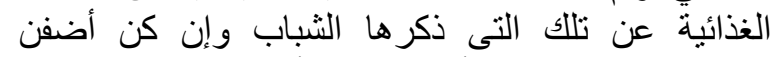

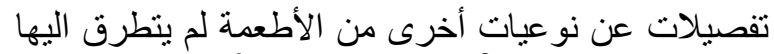
الثباب مثل "الويكه" كان بعض من هذه الأطعمة قد إندثر.

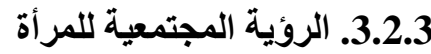

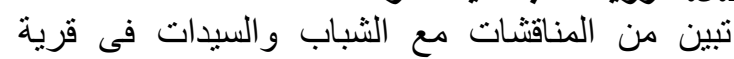

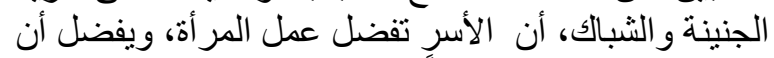

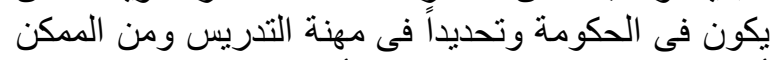

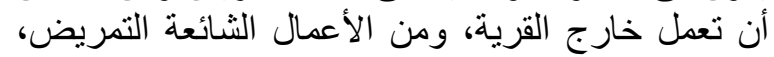

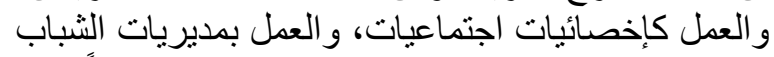

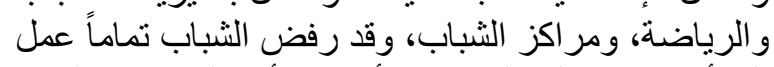

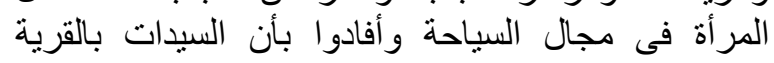

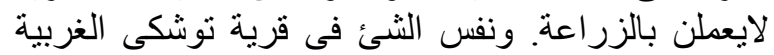

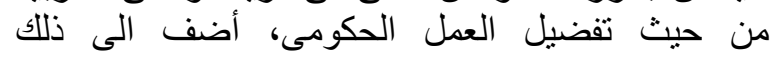
المشرو عات الصغيرة بالقرية، وكان هنالك مشغل الفيل للفتيات

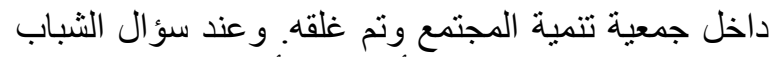

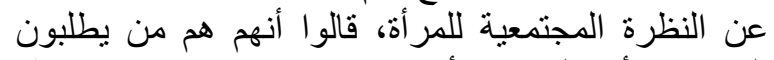

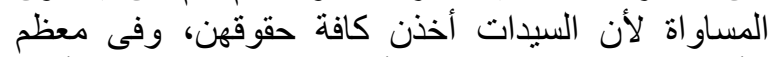

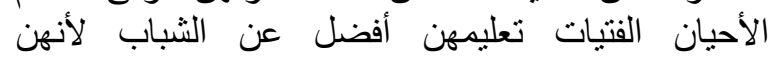

7مشروب مكون من العياه أو أحد العصائر ويضاف اليه نوع من

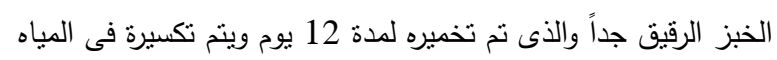

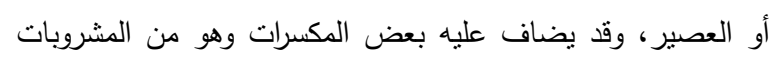

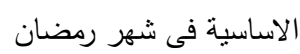

8هى البامية ولكن يتم طهوها بطريقة مختلفة عن الطريقة الثقليدية

المتعارف عليها

9خميرة بيرة ودقيق يتم خطها ثم تركها لمدة ليلة تم عجنها فى اليوم

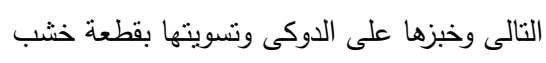

واختلف الأمر فى فرية توشكى الغربية فلا توجد

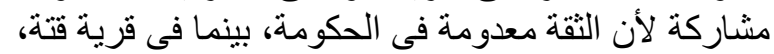

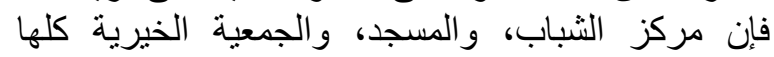

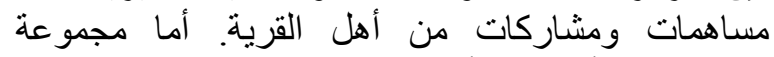

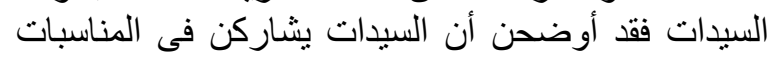

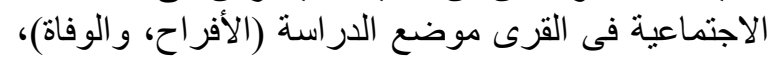

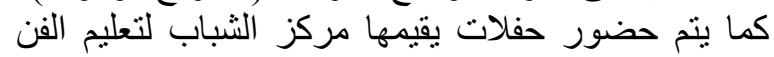

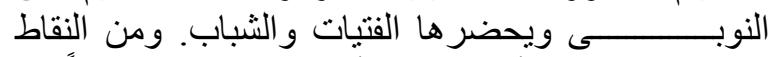

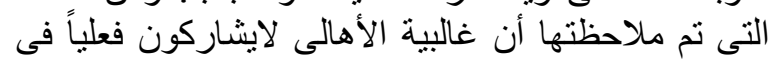

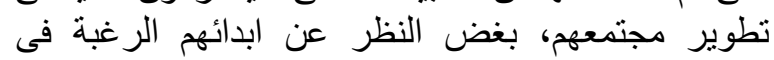

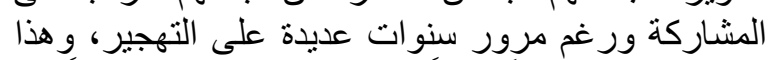

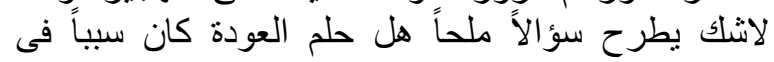

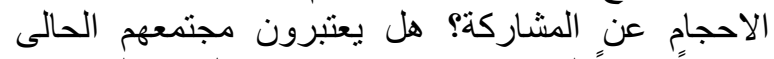

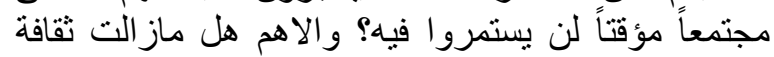

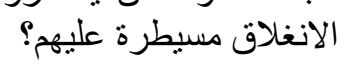
2.2.3. العادات و التقاليد

فيما يخص العادات المتعلقة بسن الزوات اليد، ذكر الشباب

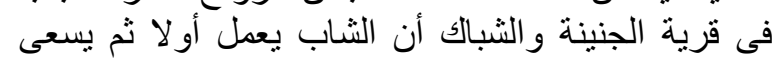

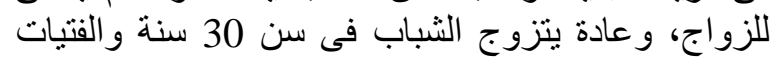

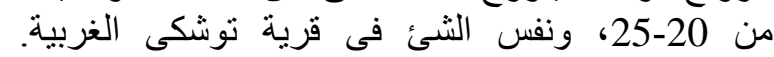

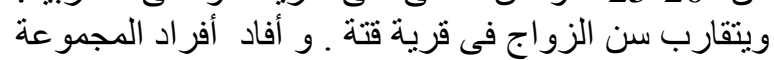

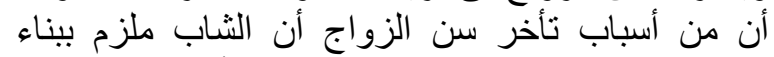

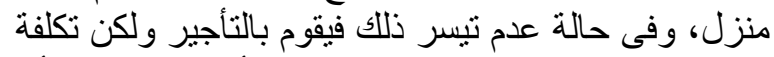

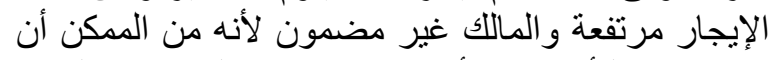

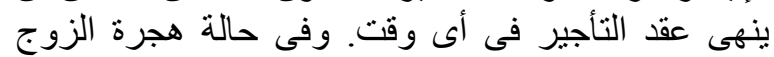

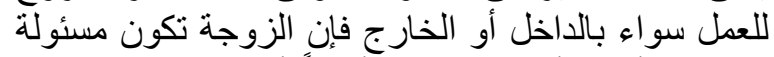

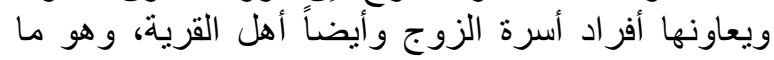

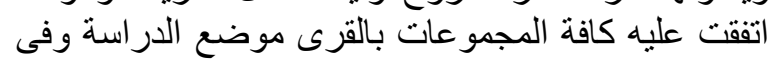

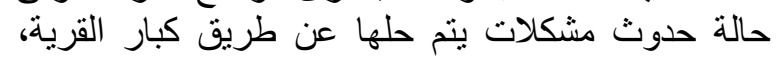

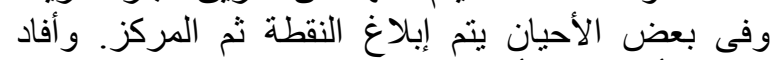

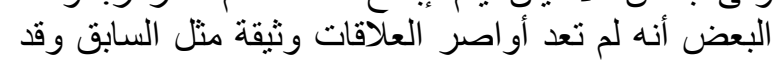
عزوا ذلك لحالة الفقر.

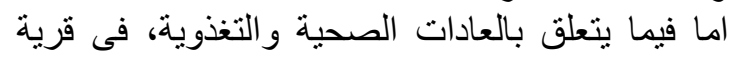

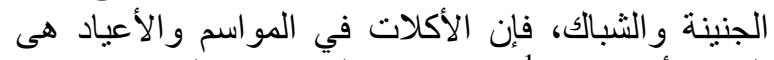

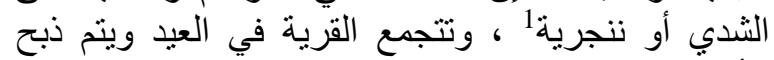

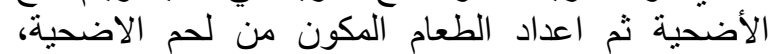

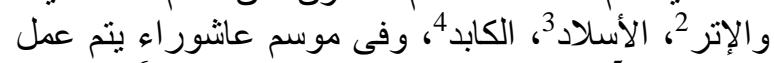

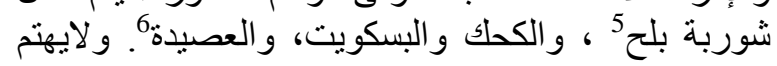

$$
\begin{aligned}
& \text { 1'نوع من الخبز الرقيق الحجم } \\
& \text { 2الملوخية والتى تطهى بطريقة معينة }
\end{aligned}
$$

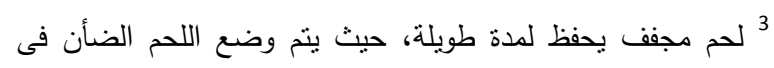

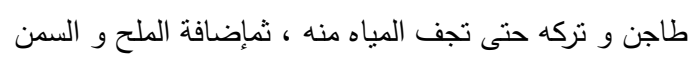
4نوع من الخبز 5ثنوربة البلح "المقلى" والمعروفة بعانوراء ولكن ينم استبدال القمح بالبلح 6 
والكروشية. و هذه الحرف تحديداً تنتشر بالقرية لأنها مهنة

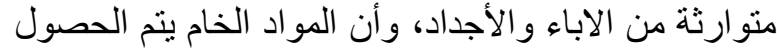
على بعضها من داخل القرية والبعض البعض الأخر من خارجها

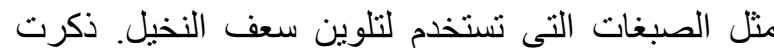

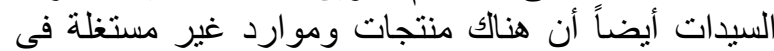

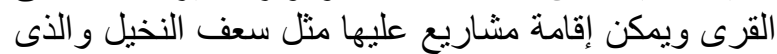

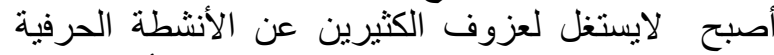

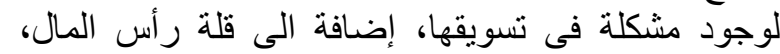

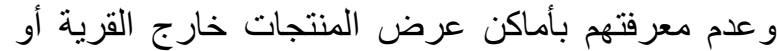

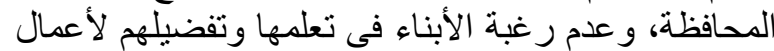

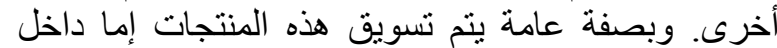
القرية أو خارجها فى الغردقة وشرم الثيخ أو سوق نصر الثنات

3.3. النتائج المتعلقة بالجوانب الزراعية_الاقتصادية

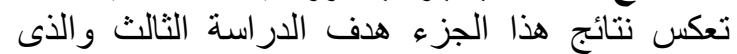

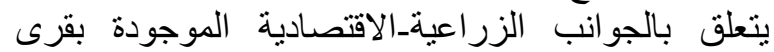

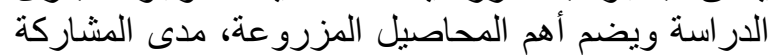

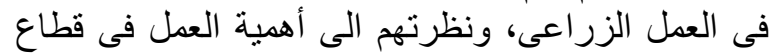

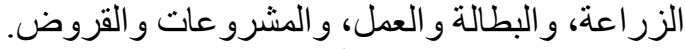

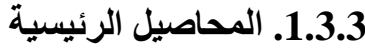
أوضحت نتائج المجموائية عات النقاثية أن من أهم

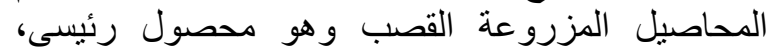
بالإضافة إلى الفول والقمح، فيما تتميز بعض القري القرى

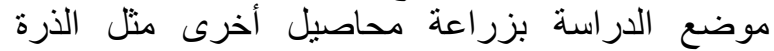

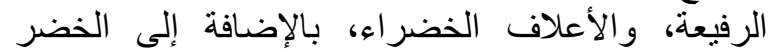

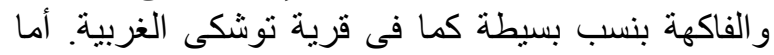

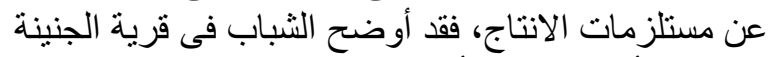

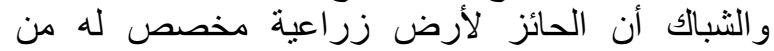
الجمعية 14 شيكارة كيماوى لفدان القصب بلرئ بعر 76 جنيه للثيكارة، ونظراً لقلة خصوبة التزبة التربة في قرية الجنينة

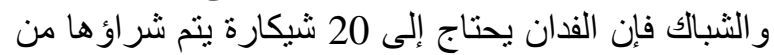

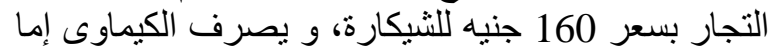

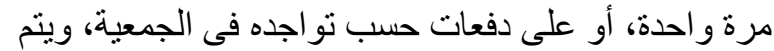

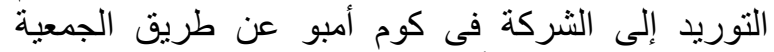

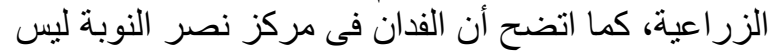

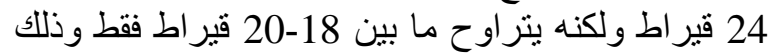

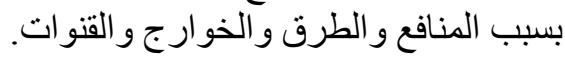

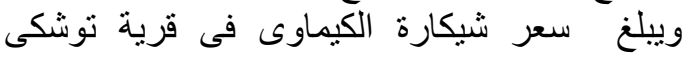

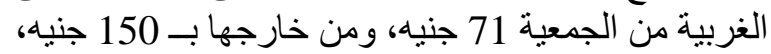

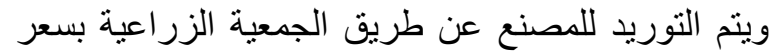

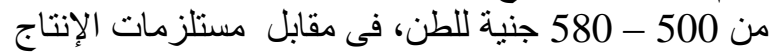

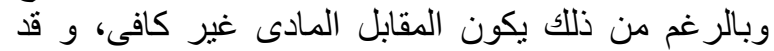

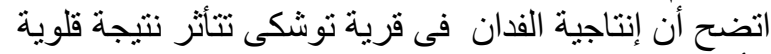

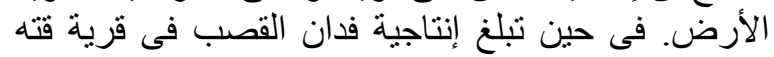

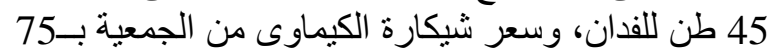

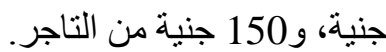
وفيما يتعلق بالمحاصيل الأخري منل الفيل الفول و القمح، فيزرع علي مصاطب فى قرية الجنينة والثبالك ويخصص التصل
مجتهدات، وقالو ا أنهم سيقومون بتعليم بناتهم فى المستقبل حتى لولم يتم تعيينهن وذللك حتى يتسنى لها تربية أو لادها

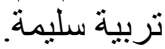

وتفضل الأسر فى قرية قته عمل المر أة، على أن يكون

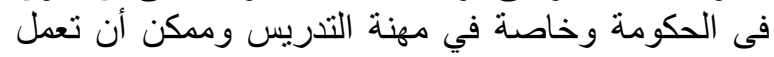

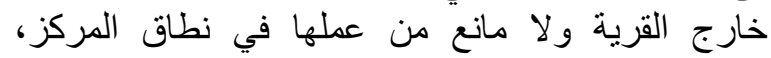
وتمارس بعض السيدات الحرف اليدوية النوبية التقليدية.

4.2.3

تلتعلق الجوانب البيئية بالتعرف على الطرقية البرق السائدة

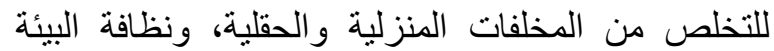

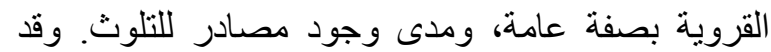

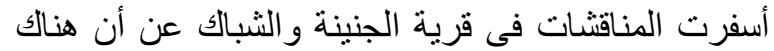

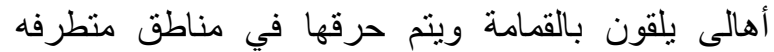

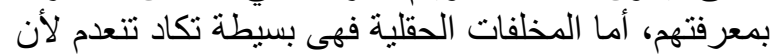

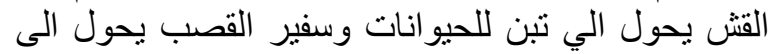

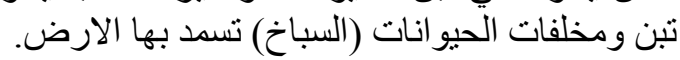

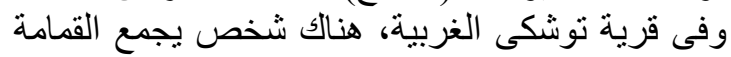

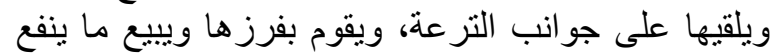

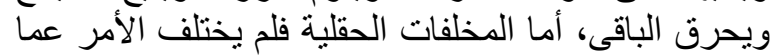

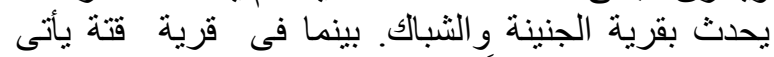

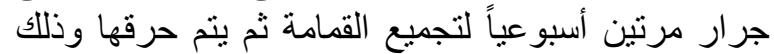
مقابل 3 جنيهات، أما المخلفات الحقلية فيتم التخلص منها كما فى القريتين السابقتين.

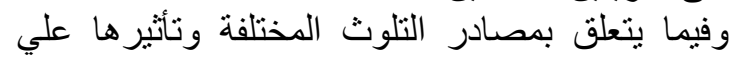

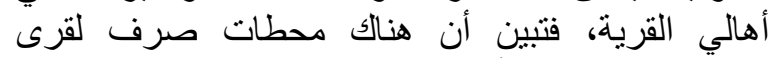

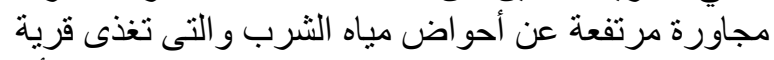

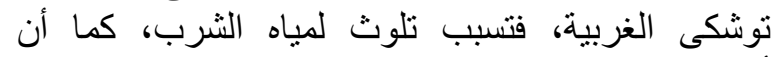

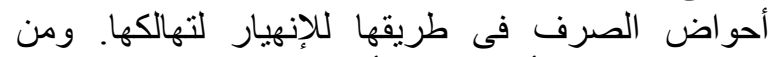

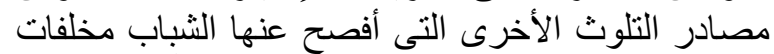

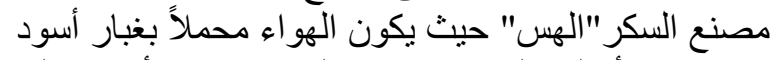

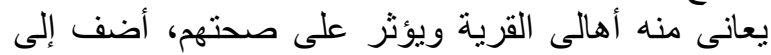

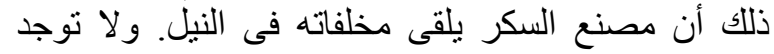

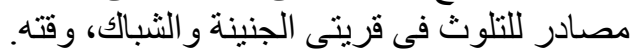
5.2.3. الحرف اليلوية والبيئية البية

تميزت النوبة قديماً بحرف يدوية ولئية وبيئية ولكن اختلف

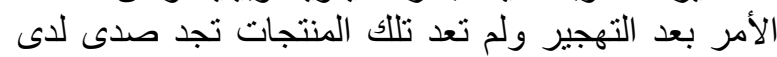

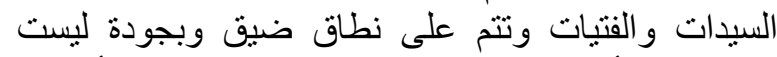

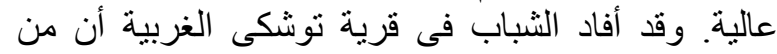

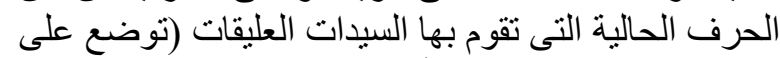

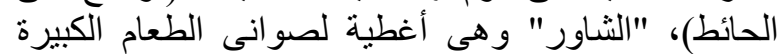

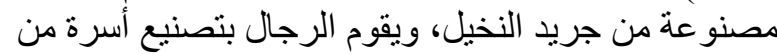

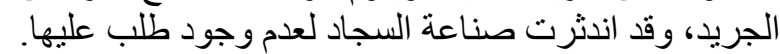

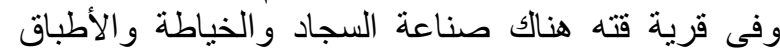

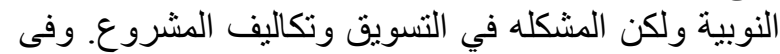

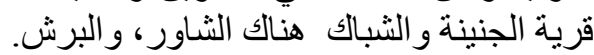

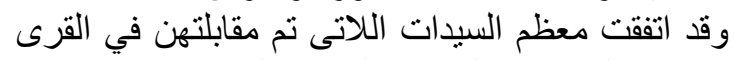

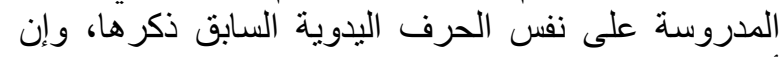
أضفن عل الخرز، و والسلال و الطواقى، و والخياطة ذورانة 
الغذائى، ذكرت مجموعات السيدات أنها أنشطة بسيطة تتمثل فى تجفف الملوخية والبامية و الفلفل في كل القرى النيدي

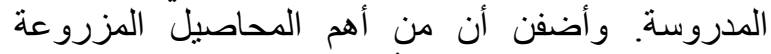

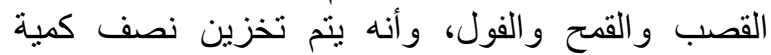

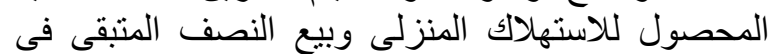
سوق القرية، وهناك محاصيل أخرى من الخضر وليع والفئر الفاكهة

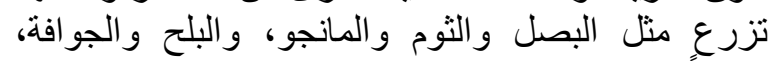

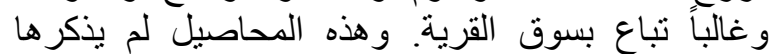

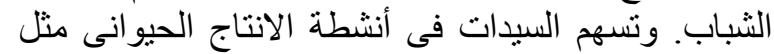

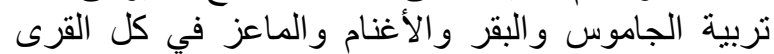

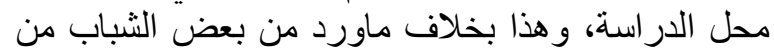

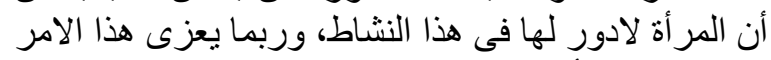

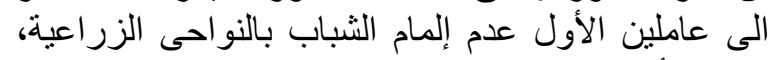
و الثانى أن السيدات دون الفتيات هن من يقمن بهذا النشاط. لألئ.

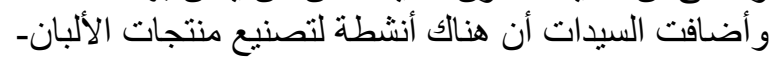

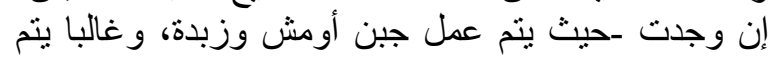

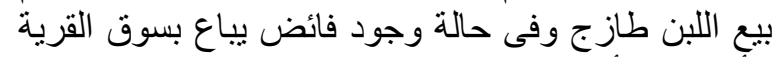

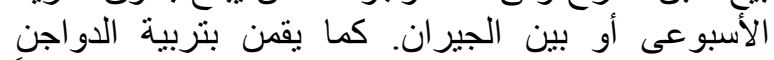

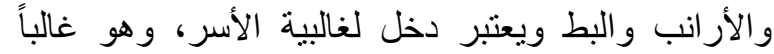
للاستهلاك المنزلى و الفائض يباع فئ سوق نصر النوبة الأبر،

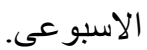

\subsection{3 أهمية القطاع الزراعى لاعي}

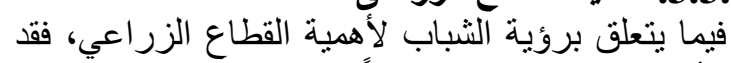

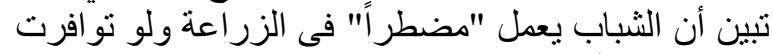

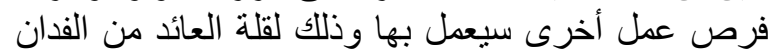
وارتفاع تكاليف الانتاج حيث تصل بلى الى نحو 3000 جنيه

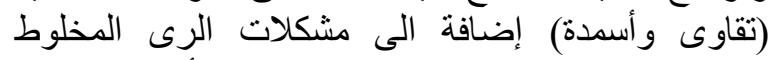

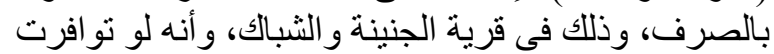

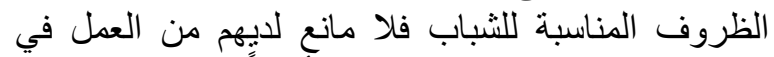

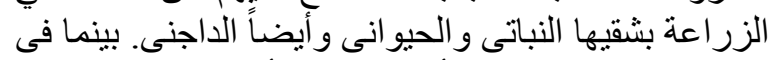

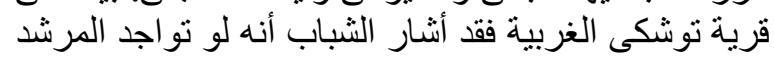

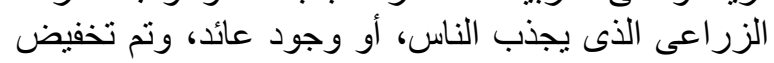

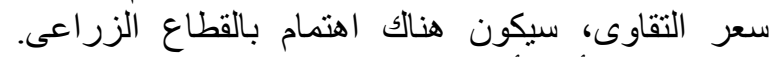

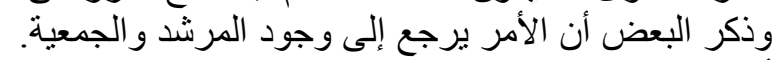

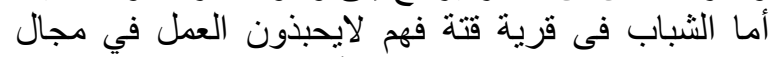

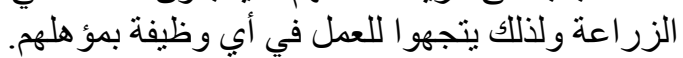

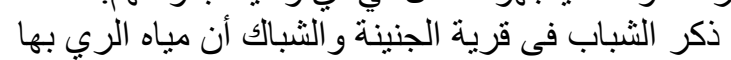

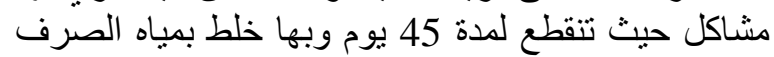

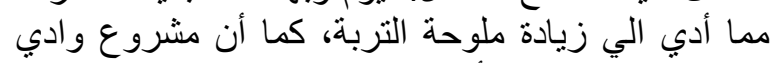

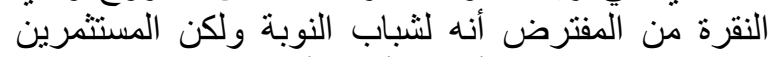

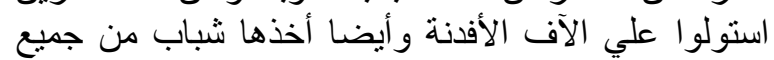

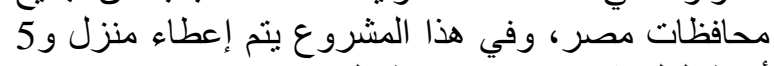

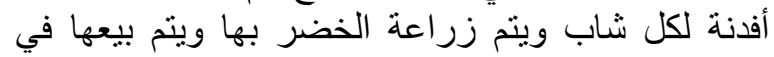
القرية.

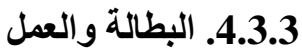
تعد نسبة البطالة مرتفعة جداً (70\%) في ولى قرية الجنينة

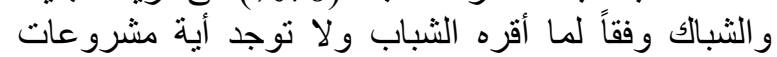

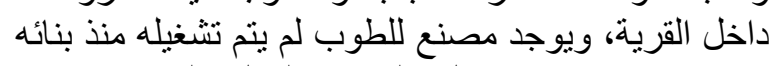
عام 1985 م، ويفضل الجميع العمل الحكومي لانه لنغله

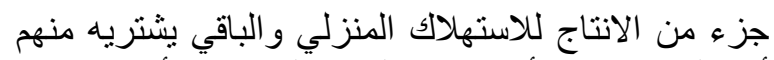

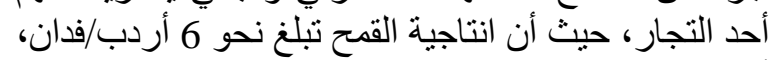

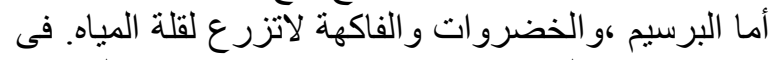

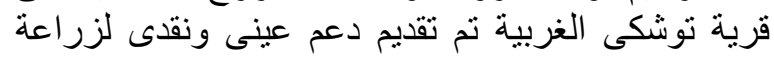

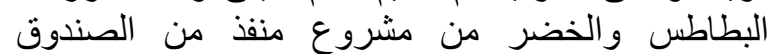

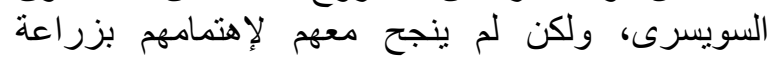

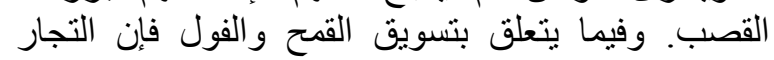

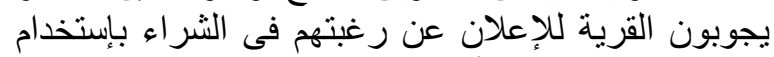

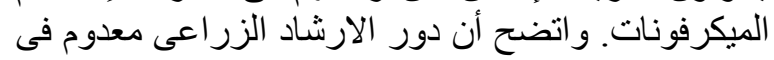

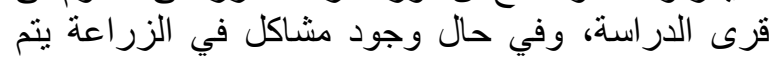

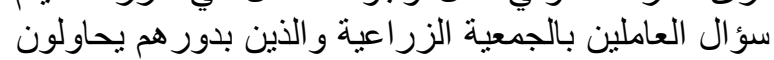

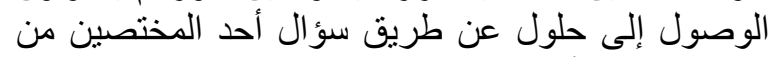
مركز البحوث إلى عن طريق عن طريق الخبر اتوات الثخصية.

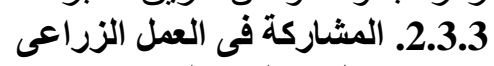

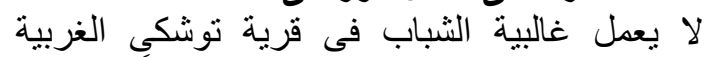

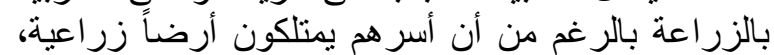

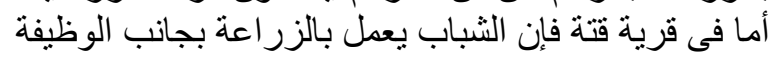

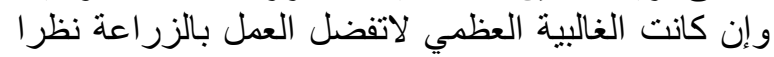

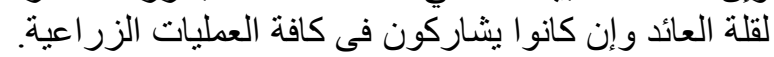

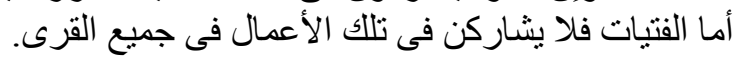

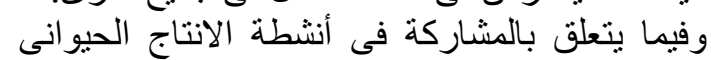

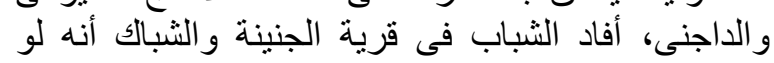

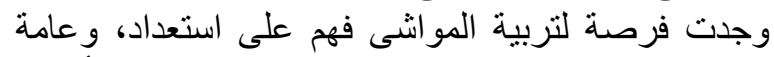

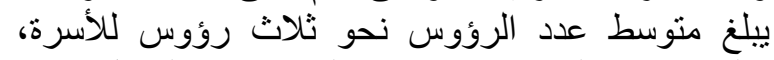

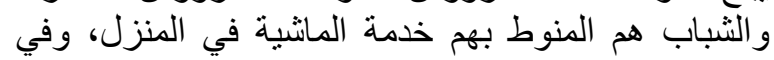
حالة مرضها يتم الذهاب الي الوحدة البيطرية بقرية البية ناصنية

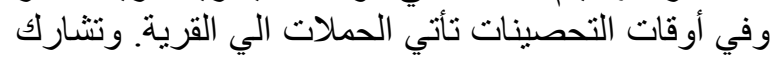

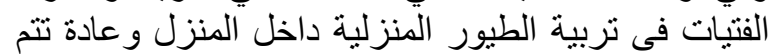
التربية لأغر اض تربية الاستهلاك المنزليولية

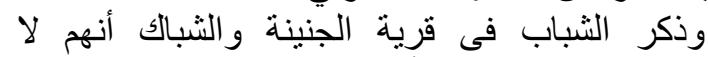

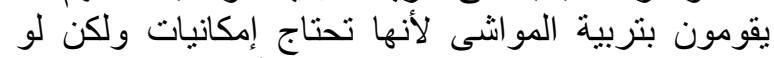

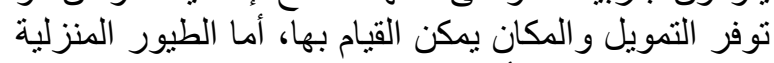

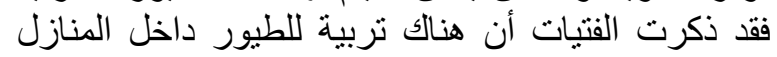
ولكن للاستهلاك المنزلى. أما مشاركة الثبات الثباب في الانتاج

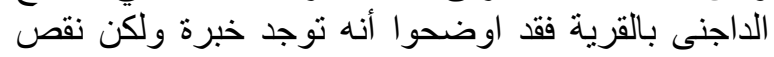

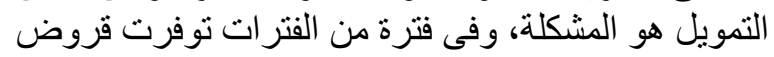

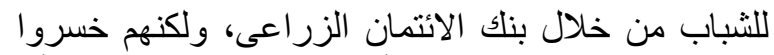

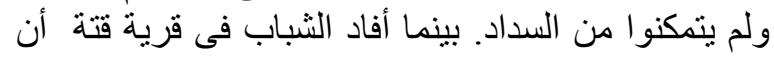

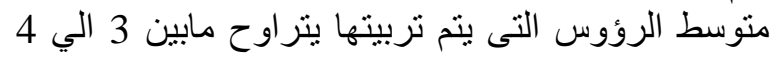

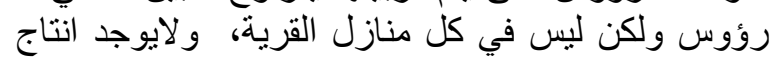

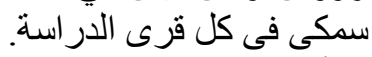

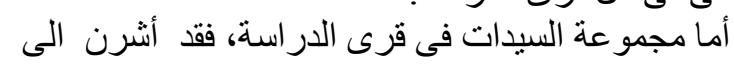

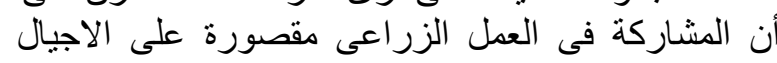

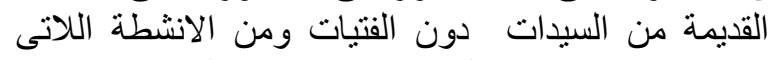

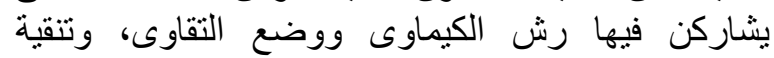

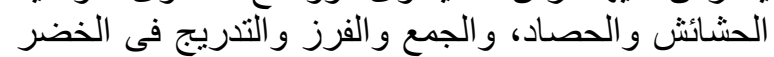

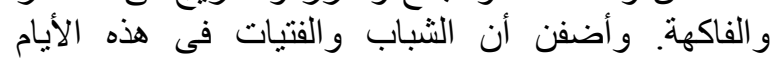

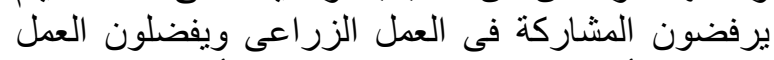
التجارى أو الحكومى. وفيما يخص النصى النشطة التصنيع التصليع 


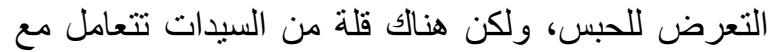
القروض متتاهية الصغر لمناسبات معينة مثل زئل زواج الأبناء.

وفى قرية توشكى الغربية ذكر الثباب أن المر أة عندها

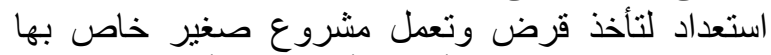

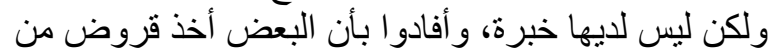

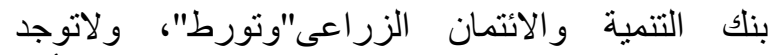

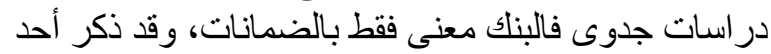

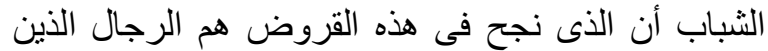

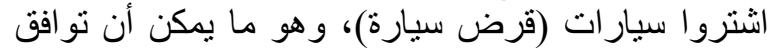
الأسرة عليه اذا كان فى نطاق القرية. لاتتعامل المرأة مع جهات الاقر اض اض ولكن الكن يمكنها عمل مشروع خاص صغير داخل المنزل.

4.3. النتائج المتعلقة بتحديد وترتيب أهم المشكلات المجتمعية النجان

تتعلق نتائج هذا الجزءء (الهدف الرئه ابع) بتحديد أهم

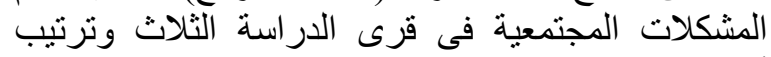

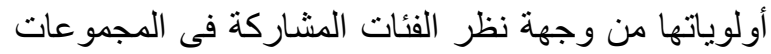

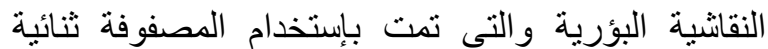
الأبعاد مع الثباب دون مجموعة لبعة السيدات نظراً لوجود

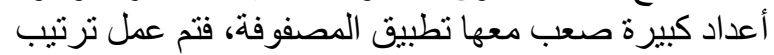

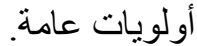

فى قرية الجنينة و الثباك ذكر الثباب خمسة مشكلات هى: مياه الرى، الوحدة الصحية، و البطالة، و عدم تشغيل

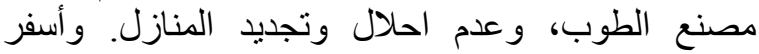
ترتيبها عن وجود مشكلتين هامتين هما: مياه الرى الرى،

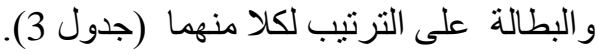

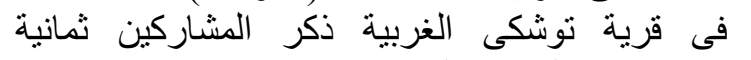

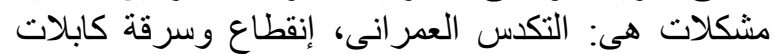

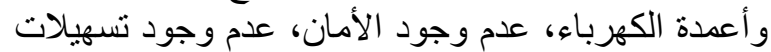

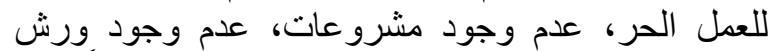
حرفية وتدرييية، عدم وجود محطة بحثية، ودئة وأخير أ تأتى

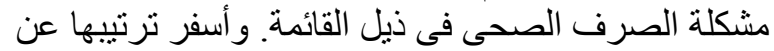

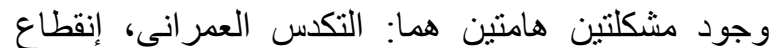

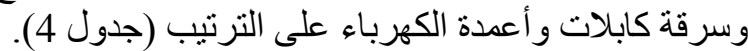

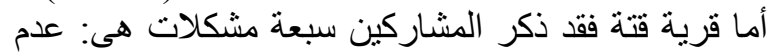

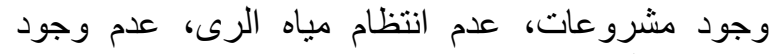

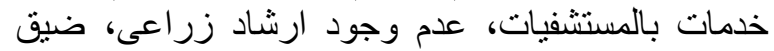
الرقعة الزراعية، عدم توفر السماد، و عدم تمليك المداء المنازل.

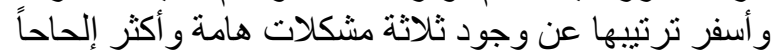

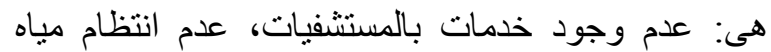

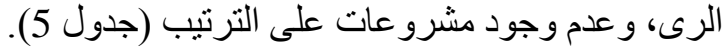
وقامت مجموعات السيدات في قرى قرى الدراسة، بتحديد مجموعة المشكلات وترتيبها حسب الوتبات أولويتها فى الحى الحل فكانت نتائج ترتيب هذه المشكلات فى القرى الخمس كما

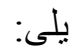
بالنسبة لقرية توشكى الغربية حددت المشاركات ثمانية مشكلات وقمن بترتيبها على النحو التالى: جاءت الت مشكلتى

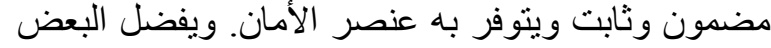

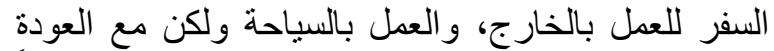

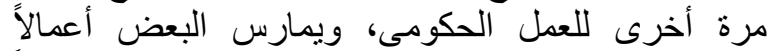

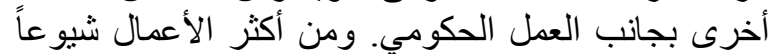

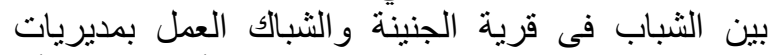

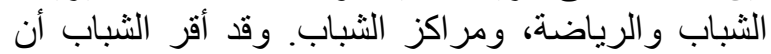

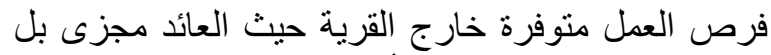

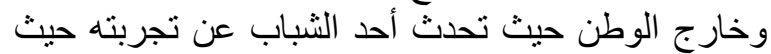

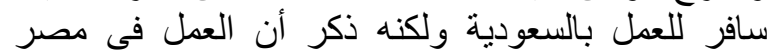

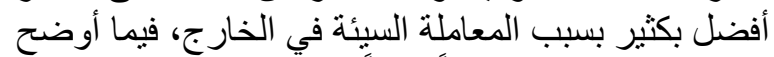

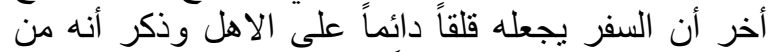
الأفضل عمل مشروع عوضاً عن السفر للخارج.

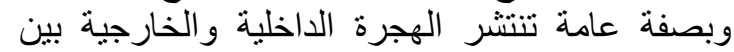

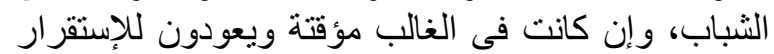

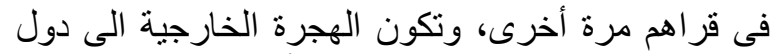

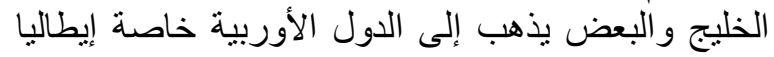

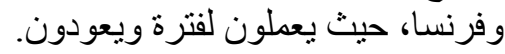

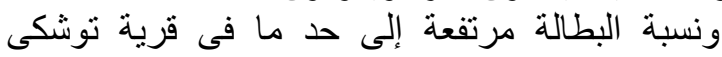
الغربية (60\%)، و يفضل بعض الفئل الثباب العمل الحر ، بينما

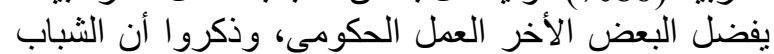

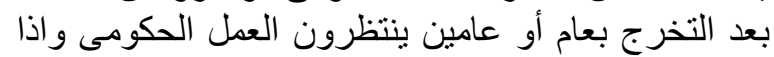

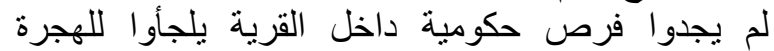

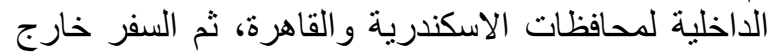

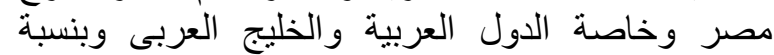

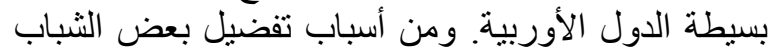

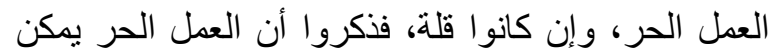

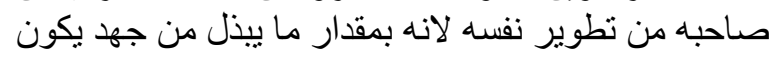

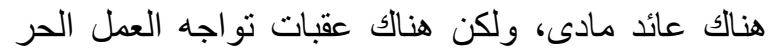

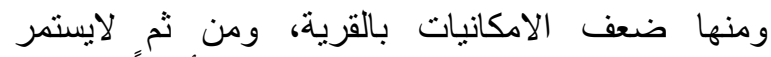

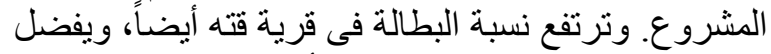

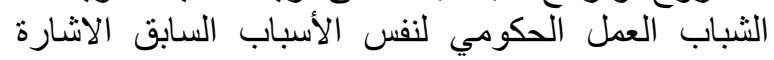

$$
\text { اليها. }
$$

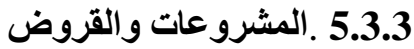

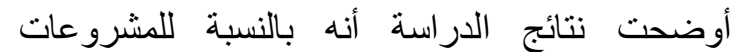
الموجوده فى القرى مثل المشروعات الثرات الزراعية (النتاج

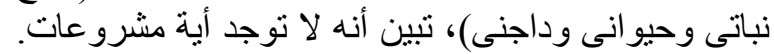

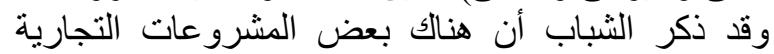

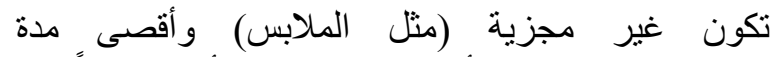

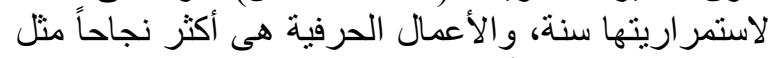

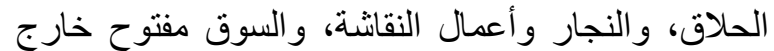

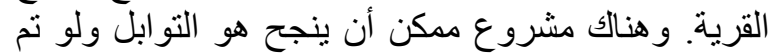
تنفيذه بالقرية والقرى المجاورة سينجح ولكن لاتنم التح زر اعتها.

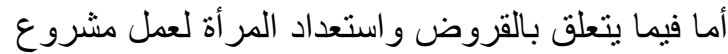

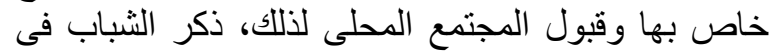

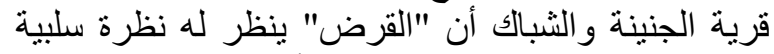

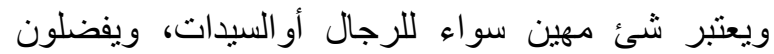
الاقتر اض من الأهل خشية عدم التمكن من سداده ومن ثلثر 


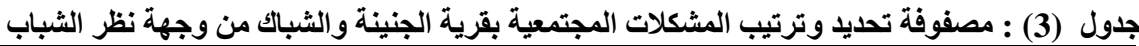

\begin{tabular}{|c|c|c|c|c|c|c|c|}
\hline الترتيب & المشكلة & عدم احلال وتجديد & علدم تثغيل مصنع & الصحية & البطالة & الرى مياه & المشكلات \\
\hline 1 & 3 & مياه الرى & مياه الرى & مياه الرى & البطالة & & مياه الرى \\
\hline 2 & 2 & البطالة & الطوب ت تثغيل مصنع & البطالة & & & البطالة \\
\hline - & - & المنازل احلال وتجديد & الطوب ت تثغيل مصنع & & & & الوحدة الصحية \\
\hline - & - & الطوب ت تثغيل مصنع & & & & & علطوب تشغيل مصنع \\
\hline - & - & & & & & & المناز احلال وتجديا \\
\hline
\end{tabular}

جدول (4): مصفوفة تحديد وترتيب المشكلات المجتمعية بقرية توشكى الغربية من وجهة نظر الثباب

\begin{tabular}{|c|c|c|c|c|c|c|c|c|c|c|}
\hline الترتيب & المشكلة & عدمة وجود & ورش حرم وجود & علام وجود & الصحى الصرف & إنقطاع وسرقة & تلعم وجود & مشروعات & العمرانى & المشكلات \\
\hline 1 & 7 & العمرانى & العمرانى & التعرانى & العمرانى & العمرانى & التعرانى & التعمرانى & & العمرانى \\
\hline 3 & 2 & مشروعات & ورش حرم وجود & علام وجود & مشروعات & إنقطاع وسرقة & تلعهيلات & & & مشرم وجود \\
\hline 3 & 2 & تلعهيلات & ورش حرفم وجود & علام وجود & تلعهيلات & إنقطاع وسرقة & & & & تلعهيلات \\
\hline 2 & 3 & إلنقاع & إنقطاع وسرقة & علام وجود & إنقطرة & & & & & إنقطاع إكهرياء \\
\hline & - & عحمة وجود & ورش حرفية وجداد & علام وجود & & & & & & الصحف \\
\hline 3 & 2 & عام وجود & علدم وجود & & & & & & & عام وجود \\
\hline- & - & عرد ورشية & & & & & & & & ورث حرثم وجود \\
\hline- & - & & & & & & & & & عدمة بحود \\
\hline
\end{tabular}


جدول (5): مصفوفة تحديد وترتيب المشكلات المجتمعية بقرية قتة من وجهة نظر الثباب

\begin{tabular}{|c|c|c|c|c|c|c|c|c|c|}
\hline الترتيب & المشكلة & علمم تمليك & علدم توفر & ضزيق الرقعة & ارشاد زراعى & غلام وجدات & مياه & مشروعات & المشكلات \\
\hline 3 & 2 & علدم تمليك & مشرو عات & ضزيق الرقعة & مشروعات & بالمستشفيات & الزياه & & مشروعات \\
\hline 2 & 3 & علم تمليك & مياه الرىى & مياه الرى انتظام & مياه الرى & بالمستشفيات & & & عياه الرى انتظام \\
\hline 1 & 4 & بالمستثفات & بالمستثفيات & بالمتشثفات & بالمستشفيتات & & & & خالمسمات وجود \\
\hline - & - & المنازل تمليك & السماد & ضزيق الرقعة & & & & & ارشاد زراعى \\
\hline - & - & علدم تمليك & الزيق الرقعة & & & & & & ضيق الرقعة \\
\hline - & - & المنازل تمليك & & & & & & & السماد توفر \\
\hline - & - & & & & & & & & المنازل تمليك \\
\hline
\end{tabular}

المرتبة الر ابعة، أما مشكلة عدم وجود وحدة صحية بالقرية

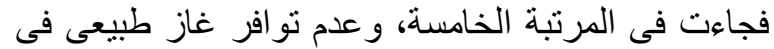

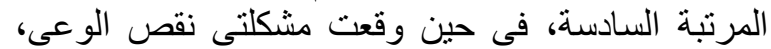

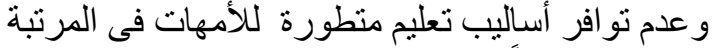

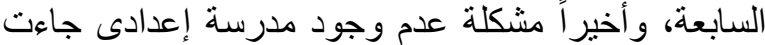
فى المرتبة الثامنة و الأخيرة .

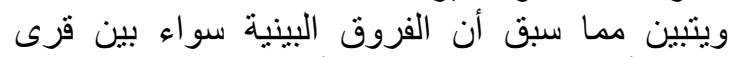

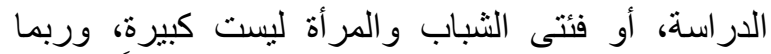

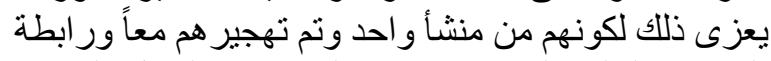
القرابة والقبلية التى تربط بين العائلات و القبائل النوبية، أضف الى ذلك أنهم يعيشون في في ظروف الفئ اجتماعية

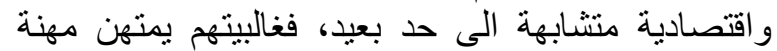

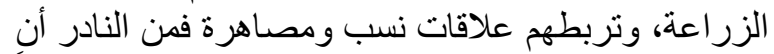

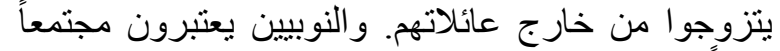

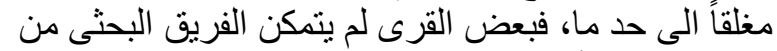

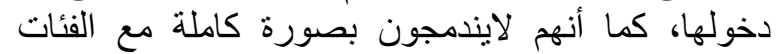

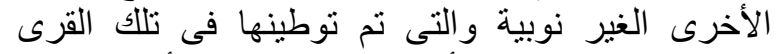

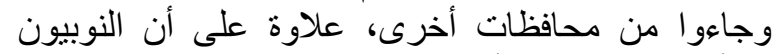
يستأجرونهم لزر اعة أر اضيهرح. كما تبين أيضاً أن الظروف أروفئ المناخية وخاصة درجـــات
الصرف الصحى، و عدم تو افر رأس مال للحرف البيائية فى المرتبة الأولى، ثم مشكلة تسويق الحرف فئ في المرتبة

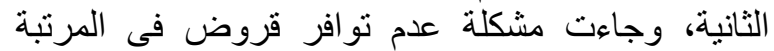

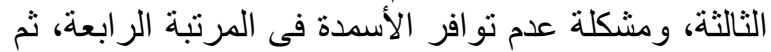

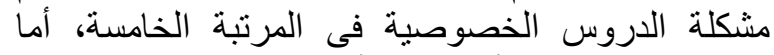

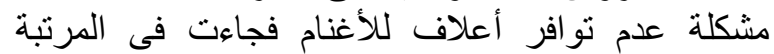
السادسة، فيما جاءت مشكلة الرعاية البيطرية في المرتبة الرية

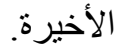

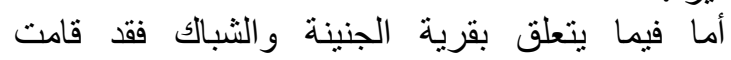
المشاركات بتحديد وترتيب ستة مشكلات كما يلى: جاءت التئية

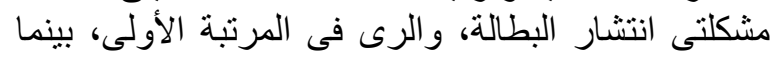

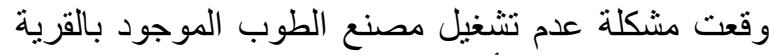

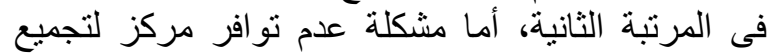
الألبان فجاءت فى المرتبة الثالثة، بينما مشكلة القمامة جاءت فى المرتبة الأخيرة.

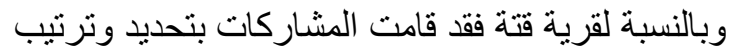

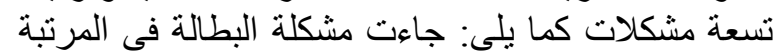

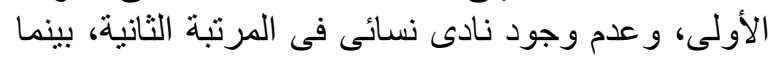

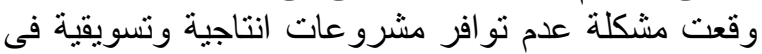

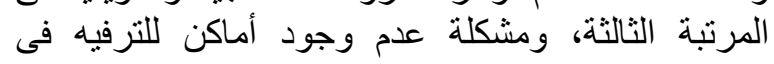


الكبار هى المسموعة، كما أن بعض الثباب ليس لديه

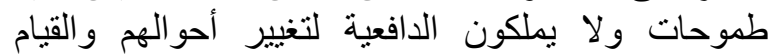

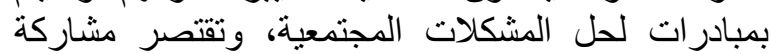
البعض منهم فى بعض الأنشطة التجميلية للقرية منل

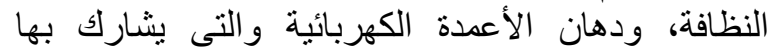

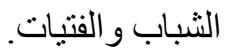
لادي المرأة النوبية مقومات وطموح للنطوير، فهن

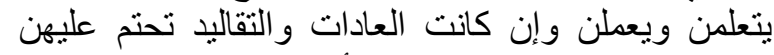
البقاء داخل قر اهم مع تفضيلهن وان لأعمال معينة مثل التندريس و التمريض. وتيضين أن غالبية الفتيات لايشاركن في الأنشطة

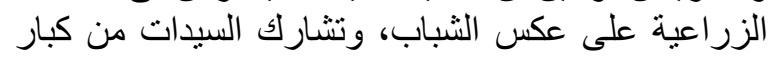

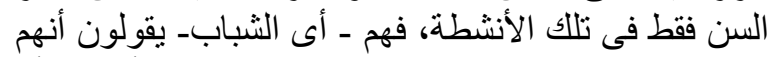

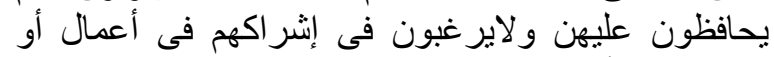

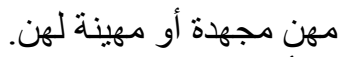

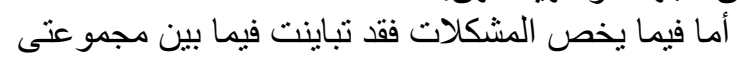

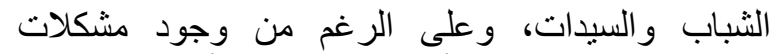

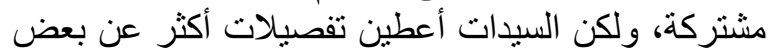

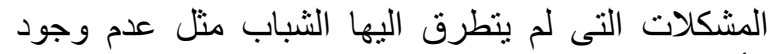

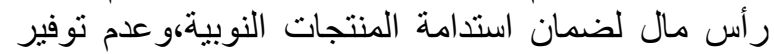

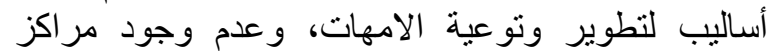

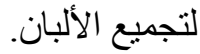

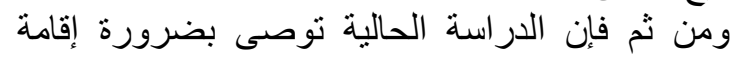

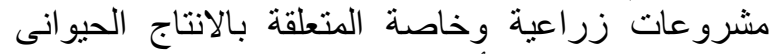

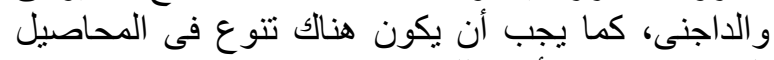

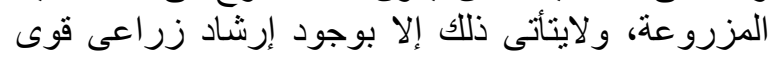

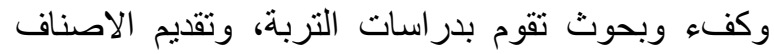

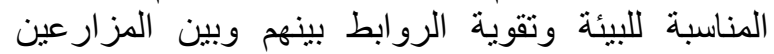

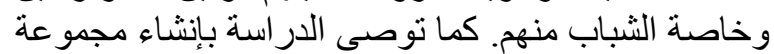

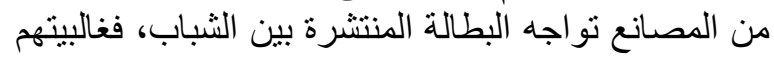

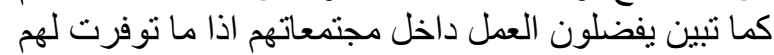

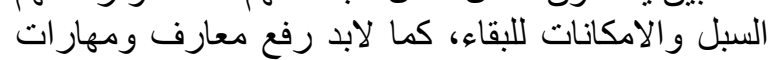

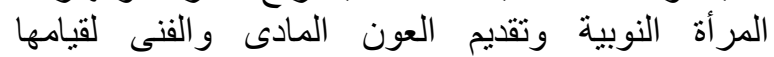

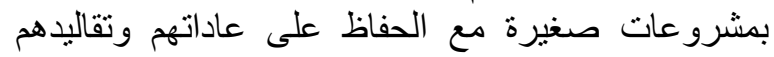

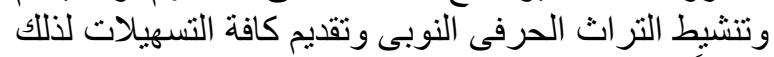

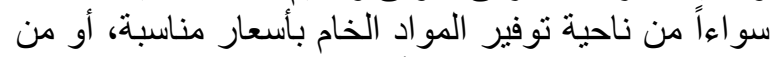

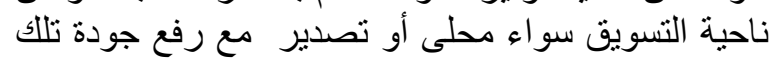
المنتجات وتطوير ها.

كما يجب تطوير بعض الخدمات الخدات المؤسية الموجودة

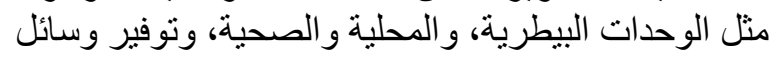

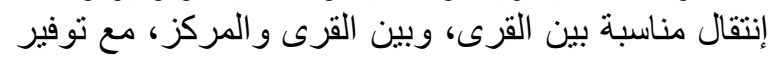
سبار ات اسعاف. وتأمل الدراسة أنه حال أخذ حزمة من الاجراءات التهات

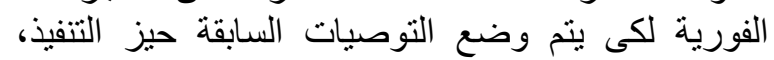

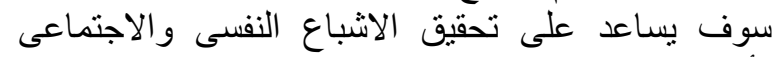

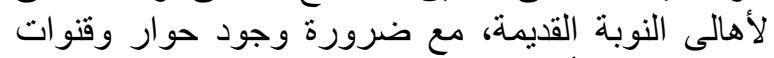

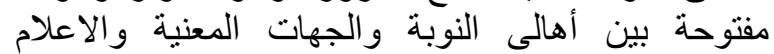

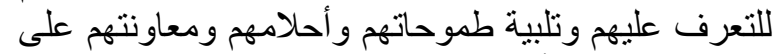

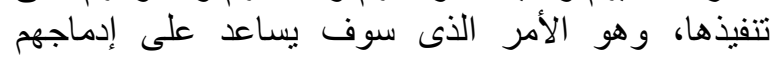
بمجتمعاتهم الجديدة، لحين تحقيق حلمهم المشروع في الأى
الحرارة المرتفعة تؤثر بصورة كبيرة على الحياة المعيشية

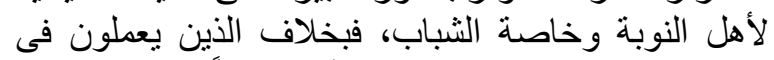

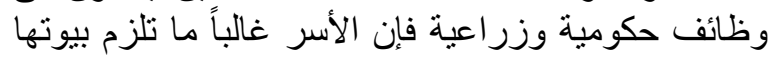

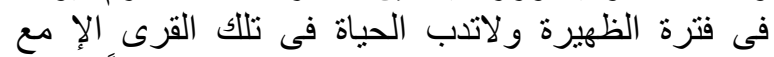

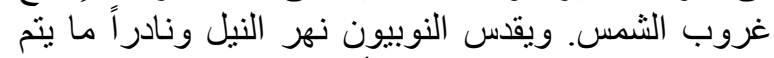

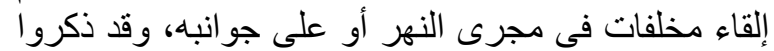

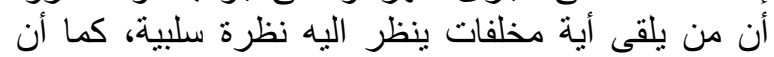

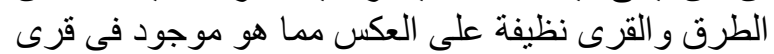

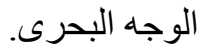

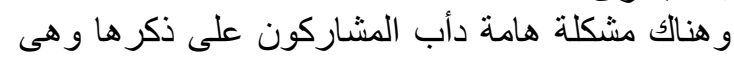

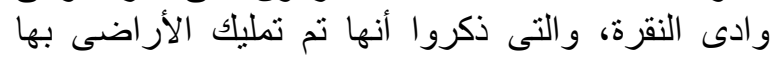

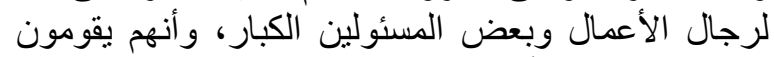

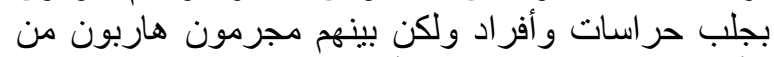

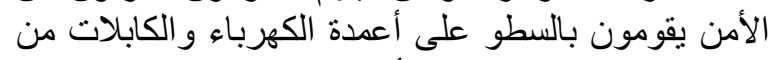

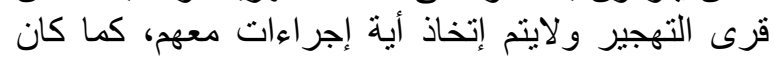

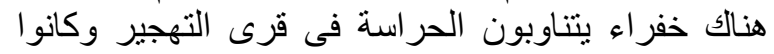

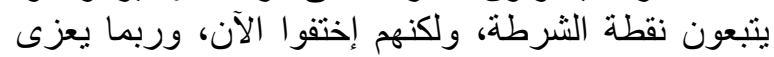

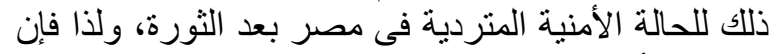
عنصر الأمان مفتقد فى تلك القرى الى الى حد ما.

\section{4. المناقشة العامة والتوصيات}

يتبين فى ضوء النتائج السابقة أن هناك التهات آثاراً سلبية

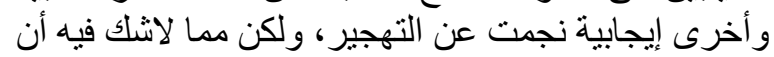

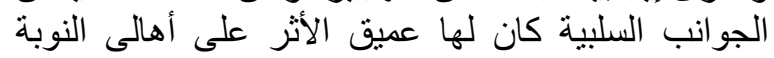

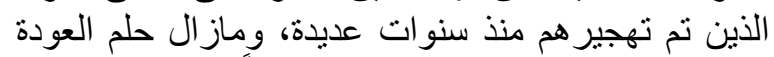

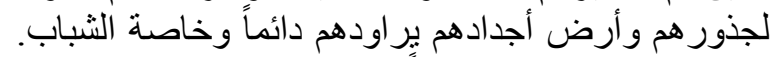

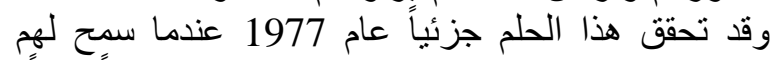
بالعودة و التوطين حول البحيرة مع اعلئ اعطائهم دعماً مالباً،

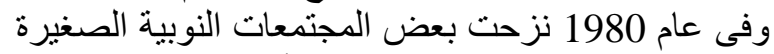

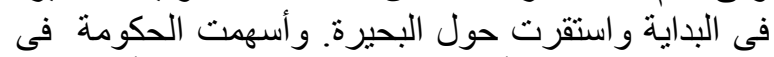

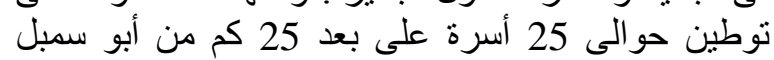
(El-Aali, 2003) و لاشك أنه قد حدث تطور في القرى خلافاً لما كان عليه

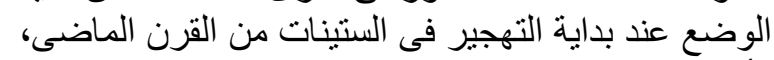

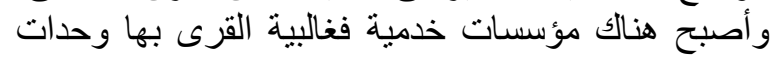

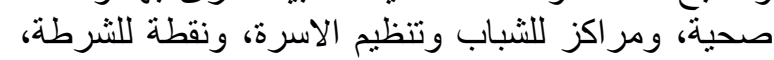

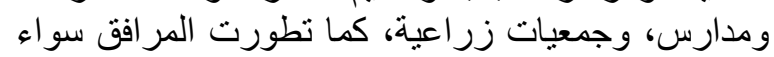
الطرق، أو الكهرباء أو المياه.

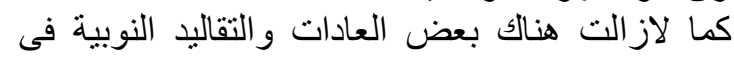

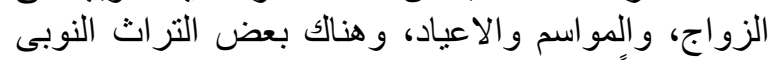

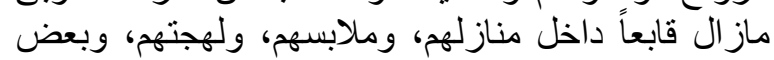

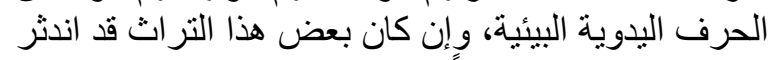

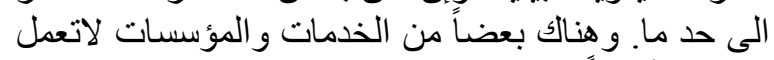

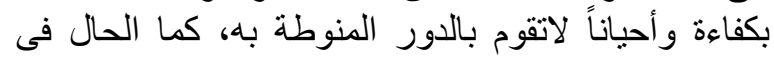

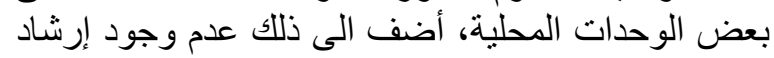
زر اعى، ووجود مشكلات متعلقة بمياه الرى الرى الرئ

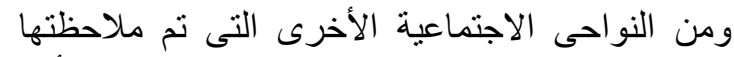

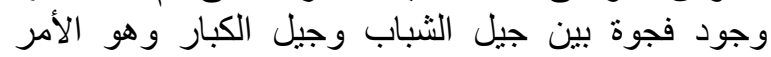

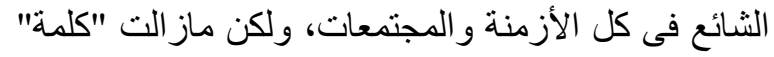


El-Aali S. (2003). the Aswan High Dam, unpublished T. Scudder manuscript, p: 8

The World Commission of Dams Report. (2000). Dams and Development, a new framework, Earthscan publications Ltd, London and Sterling, VA,UK and USA, p:28 .

Zabrana L. (2013). Abandoned Nubian Villages in Upper Egypt, material culture reviewed by social anthropological field studies, Austrian Archaeological Institute, Austria, pp: 1,2.

Zohary A. and Harrell-Bond B. (2003). Working paper on Contemporary Egyptian Migration, An overview of voluntary and forced migration, American University in Cairo, Egypt, pp: 5 \& 23.

$$
\text { فكر هم وآمالهم. أرض العرة الأجداد من خلال برنامج قومى يتبنى }
$$

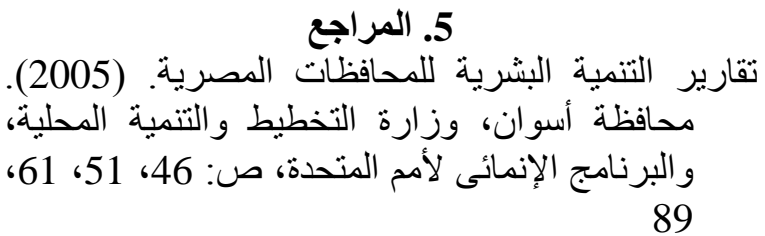

مركز الاهرام للار اسات السياسية والاستراتيجية.

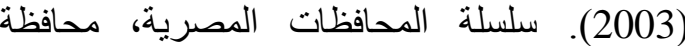

$$
\text { أسوان، القاهرة، مصر ، صل صل: } 13
$$

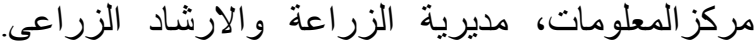

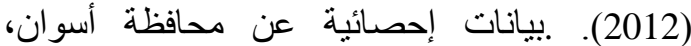

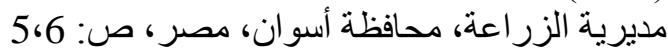

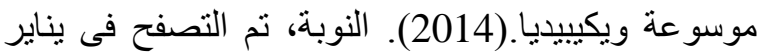

(http://en.wikipedia.org/wiki/Nuba) ،2014

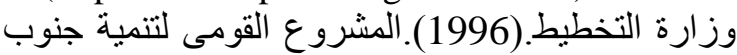

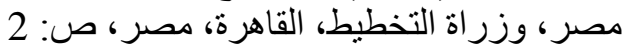

